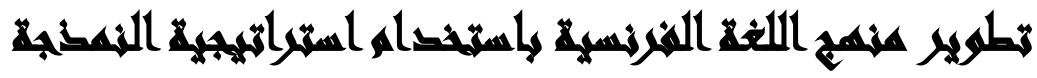

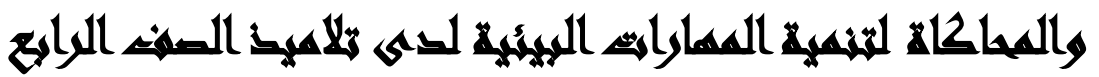 \\ الإبريسائيه
}

[11]

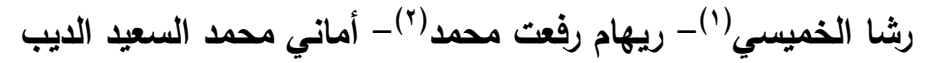

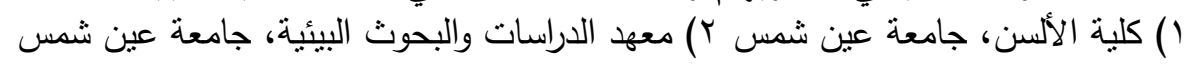

\section{المستخلص}

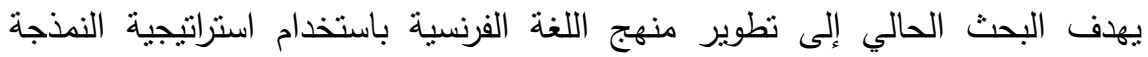

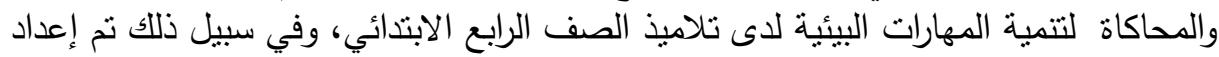

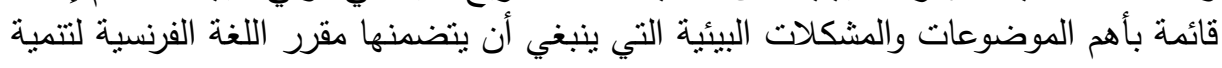

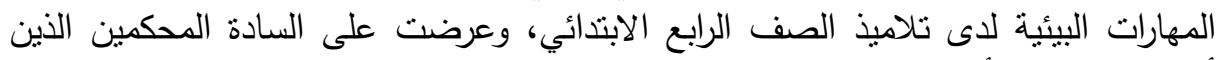

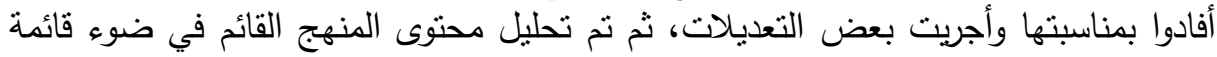

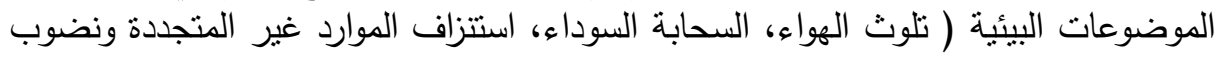

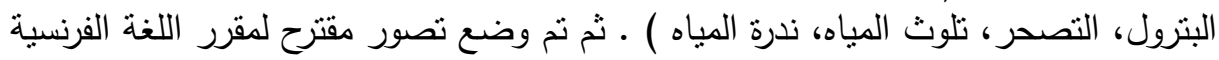

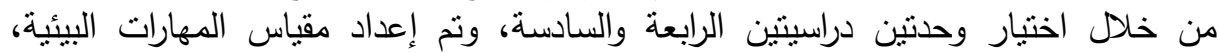

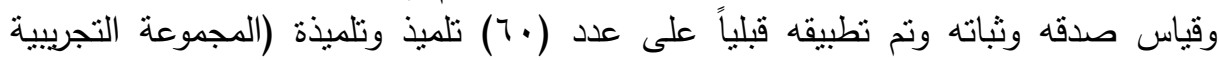

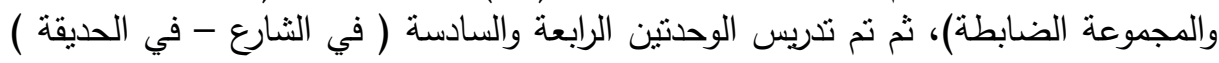

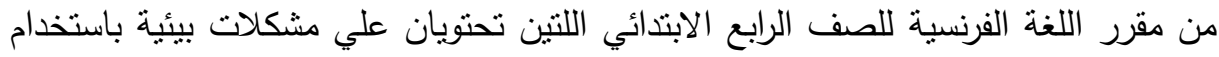

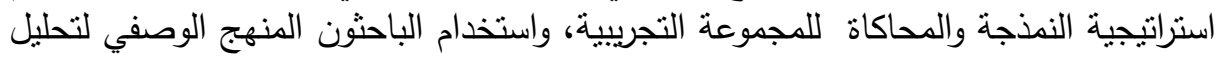

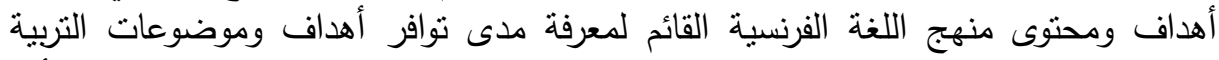

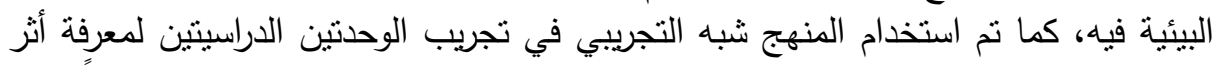

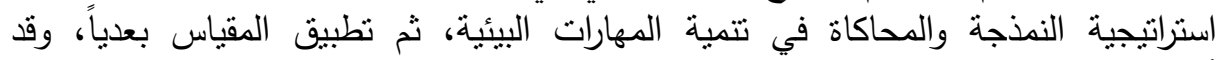

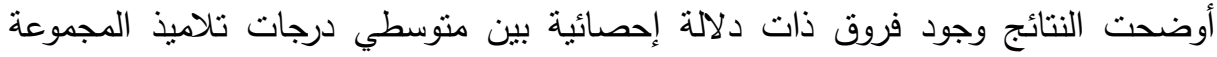

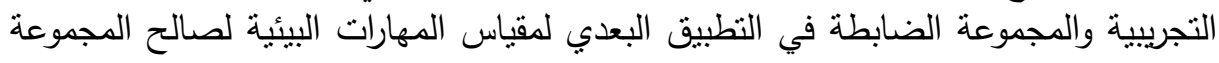

وبذلك أثنتت استراتيجية النمذجة والمحاكاة ف فعاليتها فى تتمية المهارات البيئية التي قدمها

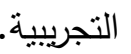

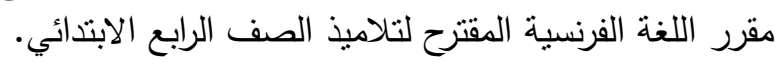

$$
\text { المجلد السابع والثلاثون، الجزء الثاني، مارس V V. r r }
$$


لذلك يمكن الاستفادة من هذا المقرر عند إعداد مناهج مرتبطة بالقضايا والمشكلات

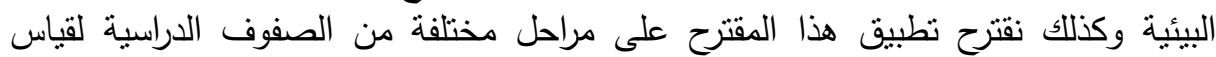

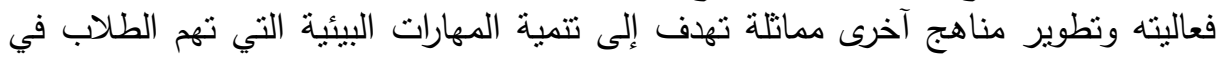
كافة المواد الدراسية بوجه عام ومناهج اللغة الفرنسية بوجه خاص.

\section{Xas}

أصبحت العلاقة بين الإنسان وبيئته من القضايا المعاصرة الملحة بعد أن وصلت هذه العلاقة إلى درجة كبيرة من التذهور والخلل، وما تمخض عن هذا الخلل من مشكلات بيئية

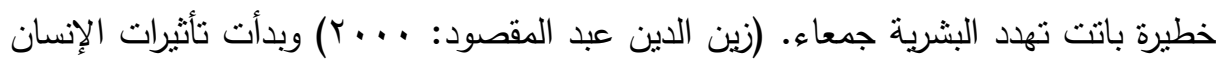

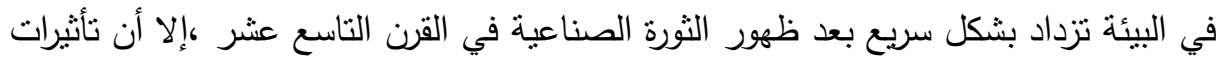

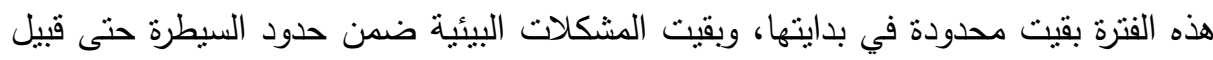

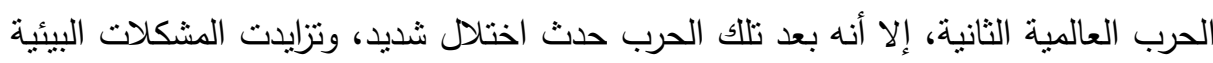
بشكل كبير بما ساهم في اختلال التوازن البيئي، ويمكن القول بأن التربية تشكل محاولة

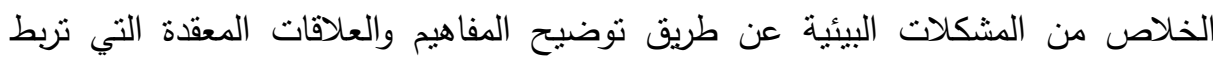

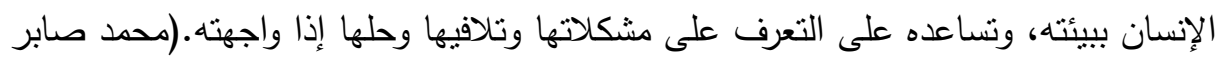

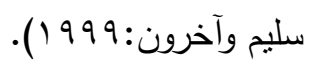

ومن هنا ظهر فرع جديد للتربية هي التربية البيئية التي تعتبر فرعا قديم الوجود، باعتبار

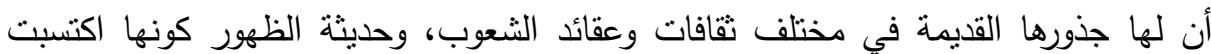

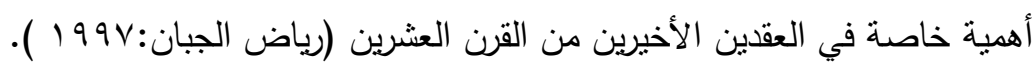
لذللك جاءت صيحات المؤتمرات واللقاءات الدولية التي تعنى بالإنسان والحياة مؤكدة للتربوبين وللمتخصصين عموماً في جميع العلوم بأن بعطى المنهج الوقت الكافي لبناء سلوك بلون بيئي واع عند الإنسان عبر مناهج ومراحل تعليمية وتدريسية، كما أن المراجعة البسيطة لمقررات المؤتمرات العالمية في استوكهولم عامجY9r وبلغراد عام 19V0 وتبليسي عام 199V نظهر تأكيد هذه اللقاءات على ضرورة بناء مناهج دراسية تعنى بشئون خلق الإدراك 
الواعي لمخاطر إهمال التربية البيئية كهدف سلوكي مطلوب يتحقق من خلال المدارس والمعاهد والكليات (أكرم العزاوي: ل . . r). ومن هنا فإنه يتعين على المؤسسات التعليمية (المدارس، المعاهد، الجامعات) ضرورة تضمين المفاهيم البيئية في مناهجها التربوية في مجالاتها العلمية والنفسية والاجتماعية والاقتصادية لمواجهة المشكلات البيئية (محمود حميد:؟ . . ب).

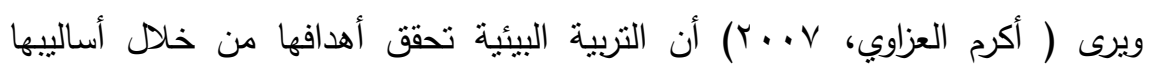
وطرائقها وتفاعلها من خلال المناهج الدراسية تحقق تكاملية المعرفة وليس تجزئتها، وإن هذه الهن التكاملية غير ممكنة أو لبيت سهلة التطبيق عند بعض من واضعي المناهج لكنها ضرورة ملزمة يجب أن تدخلها التربية من خلال مفرداتها كما يجب أن تعطى تلك المفردات للبيئة مكانتها وأن التكامل في المعرفة معناه وحدة الأجزاء وترابطها بطريقة ما تمكن المتعلم من فن فئل تعلمها.

ويرى الباحثون أن نطوير المناهج في ضوء أهداف التربية البيئية له أهمية كبرى ومكانة

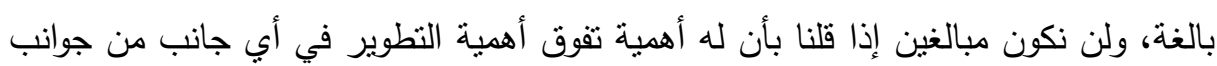
الحياة، ذلك لأن تطوير المناهج معناه في الواقع تطوير في بناء وإعداد إنسان المستقبل .

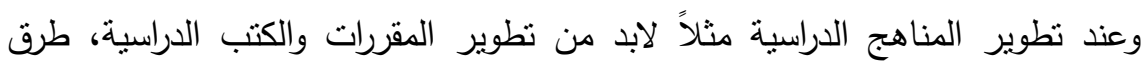

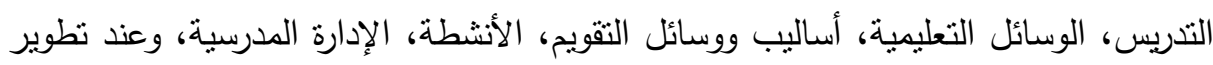

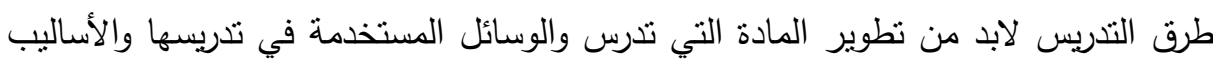

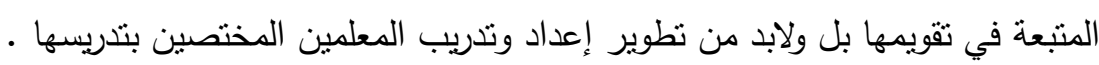

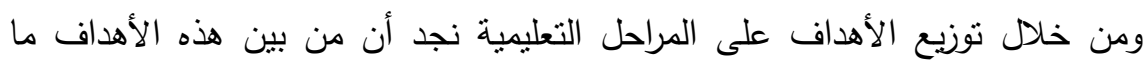

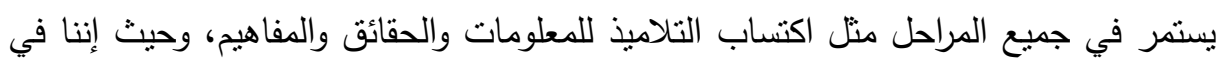
عصر الانفجار المعرفي فإن اكتساب التلاميذ للمعلومات يمتد لكي يشمل جميع المراحل التعليمية، بل ولقد ثبت أخيراً أن الطالب حتى بعد تخرجه مطاب التبالب بالاستمرار في تحصيل

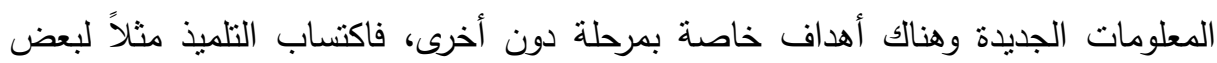


العادات مثل عادة النظافة أو بعض المهارات منل مهارة القراءة والكتابة خاصة بالمرحلة

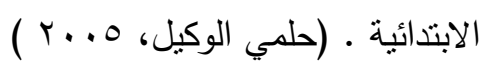

فإذا كانت اللغة موقف إنساني فهي طبيعة اجتماعية تسمح للأفراد بالاتصال حيث تبادل الأفكار فتعلم اللغة الفرنسية في جمهورية مصر العربية ضرورياً نتيجة الموقع الجغرافي للبلاد ومن أجل الاحتباجات الراهنة فنحن نحتاج لتبادل الآراء في شتى المجالات. ( حنان حلهي،

ويقول ( واصف أمين جرجس، 99 1)) إن الهرف الأكثر أهمية في تعلم اللغات وخاصة اللغة الفرنسية هو الهدف الإجرائي ( السلوكي ) وذلك بتحقيق اقتتاء الطالب الكلمات

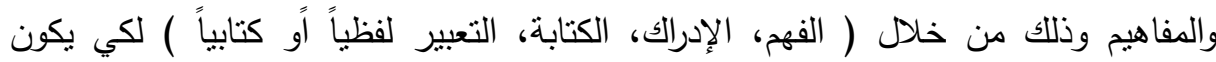
المتعلم قادراً على فهم نص سهل وليسمع محادثة بسيطة وأن يستطيع التلميذ أن يروي التفاصيل التي تحدث في شكل مقالة في مجلة أو جريدة، أما الهدف الآخر هو الهدف ولهن التقافي فالمتعلم للغة الأجنبية يستطيع الاكتشاف للمفاهيم الجديدة من خلال القضايا المعاصرة والمحيطة به عالمياً حيث مفردات الكلمات والأفكار الأكثر أهمية من أجل الإفادة ومن جهة لإنها

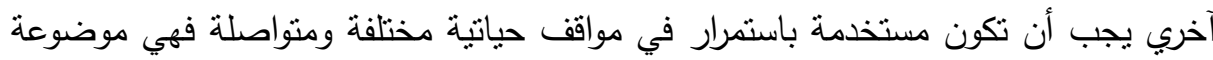

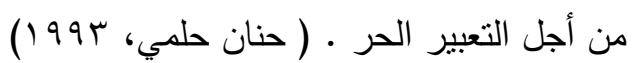
هذا ويري الباحثون أن مناهج التعليم في مصر معنية آنية بتضمين القضايا البيئية وتحقيق أهداف التربية البيئية وخاصة مناهج اللغات ،غير أنه من خلال مراجعة وتحليل محتوى منهج

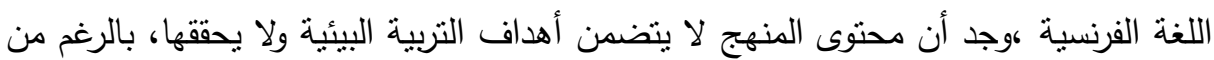
تتاوله لبعض الوحدات التي تحمل بداخلها مصطلحات البيئة الطبيعية إلا أنه تتاول موضوعاته من منظور لغوي بحت، كما ركز على تتمية الأهداف المعرفية ولم يراعي تتمية الجوانب الوجدانية والمهارية، وتضمن محتوى المنهج القائم الذي نم توزيع موضوعاته في

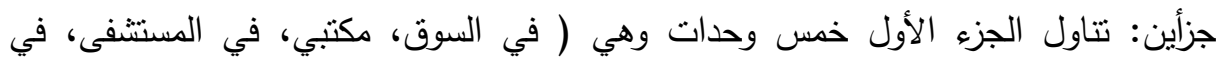
الثارع، عيد الميلاد ) أي علاقة التلميذ بما يحدث في حياته اليومية وبيئته المحيطة ،ونتائج هذه العلاقة في النعرف على بعض المفاهيم والمشكلات البيئية، وأثز ذلك في تمثنيل وتتظير

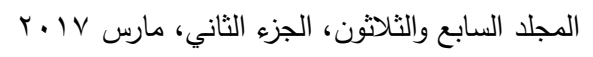


مجاله اللغوي، بينما تتاول الجزء الثاني ( الموسيقى، في الحديقة، علي الثاطئ، في النادي،

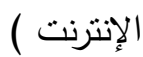

وهنا تتضح علاقة التلميذ بظواهر المناخ والمياه والنبات والحيوانات تأثيراً وتأثراً، ونظم المحتوى على هيئة وحدات تعليمية تتكامل فيما بينها محققة أهدافها المسجلة في بداية كل منها، غير أنها أهداف معرفية بحتة لا تحقق أهداف التربية البيئية، كما أن محتوى المنهج لم فئل

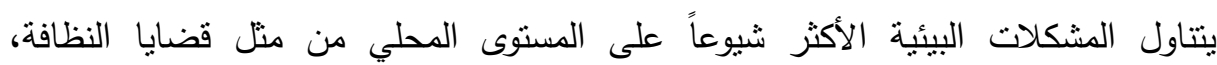

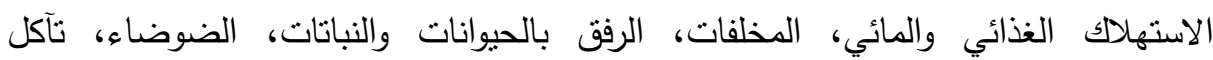

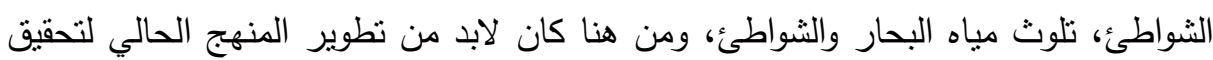
المهارات البيئية وهو ما بسعى إليه البحث الحالي.

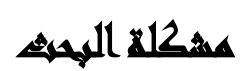

شعر الباحتون بمشكلة البحث الحالي من خلال تدريسهم لمنهج اللغة الفرنسية في الفترة

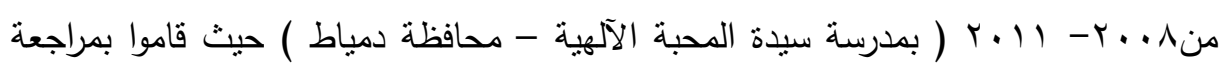

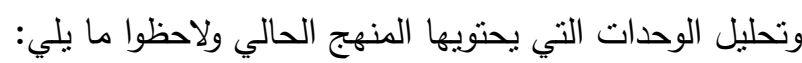

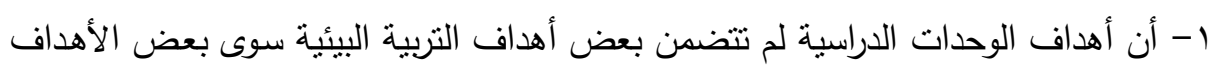

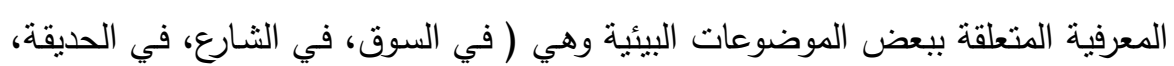

$$
\text { علي الثاطئ ) }
$$

ץ- أن المنهج عبـارة عن إطـار بيئي معرفي فقط لا بتضـمن الجـانبين الوجداني والمهاري وبالتالي لا يحقق أهداف التربية البيئية.

وهذا يدل على قصور المنهج الحالي في تتاول جوانب التربية البيئية وتحقيق أهدافها. وقد دعم هذا المطلب آراء بعض الموجهين والمعلمين القائمين على تدريس المنهج،

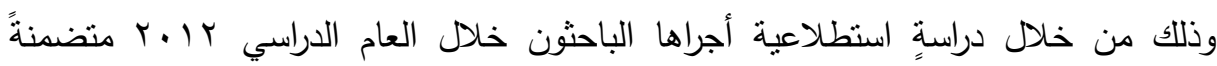
استبيانٍ مكون من (0) أسئلة نم عرضها على عدد من من الموجهين والمعلمين وكانت آرائهم تصب في إطار قصور المنهج في تحقيق أهداف التربية البيئية، وذلك على النحو الآتي:

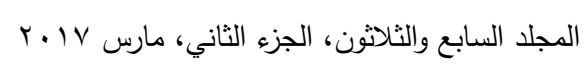


• أن نسبة (•^\%) أثناروا إلى عدم مراعاة تضمين أهداف وموضوعات التربية البيئية عند

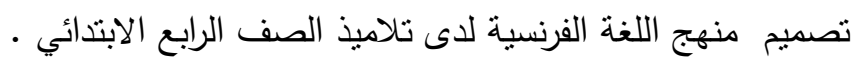
• أن نسبة (10\%) أنثاروا إلى عدم مراعاة المنهج للبعد البيئي على الرغم من أن محتواه

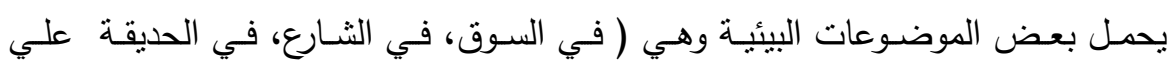
الثناطئ ) • أن نسبة (•9\%) أنثاروا إلى ضرورة تطوير منهج اللغة الفرنسية لتحقيق بعض أهداف التربية البيئية. • أن نسبة (^^^) أثناروا إلى أهيـة استخدام استراتيجيات تدريسية متتوعة لتتميـة أهداف

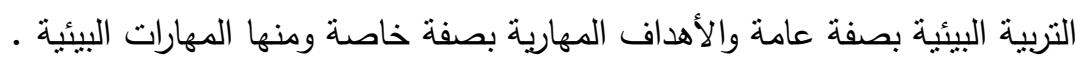

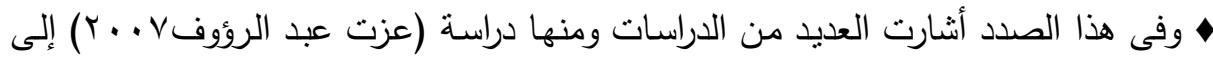

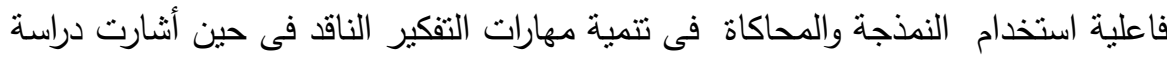

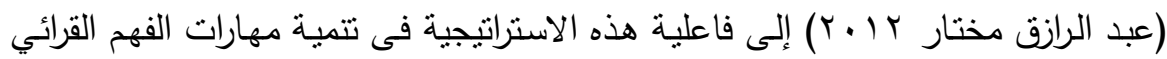
لاى طلاب الصف السادس الابتدائي بالمدارس الصديقة للفتيات.

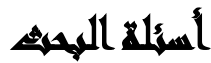

تمثلت مشكلة البحث الحالي في السؤال الرئيسى التالي: - ما التصور المقترح لتطوير منهج اللغة الفرنسية باستخدام استراتيجية النمذجة والمحاكاة لتوبية لتنمية المهارات البيئية لاى تلاميذ الصف الرابع الابتائي؟ ويتفرع عن هذا السؤال الأسئلة الفرعية التالية: 1- ما الموضوعات البيئية التي ينبغي أن يتضمنها مقرر اللغة الفرنسية باستخدام استراتيجية

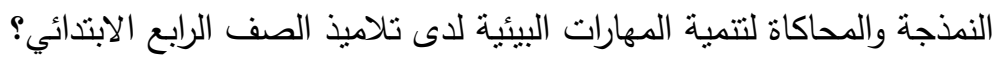
r- ما مدى نوافر تللك الموضوعات في المنهج الحالي للغة الفرنسية؟ r- ما الإطار العام للتصور المقترح لنطوير منهج اللغة الفرنسية؟ 
رشا الخيسي وآخرون

ع- ما فاعلية تدريس وحدتين من هذا الإطار المقترح للمنهج المطور باستخدام استراتيجية

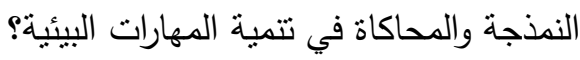

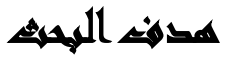

تتمية المهارات البيئية لاى تلاميذ الصف الرابع الابتدائي من خلال نطوير منهج اللغة الفرنسية.

\section{Aatl}

$$
\text { تتقسم حدود البحث إلى: }
$$

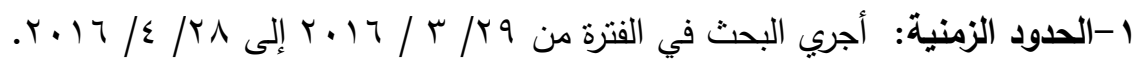
r-الحدود البشرية: نم تطبيق الدراسة على مجموعة من تلاميذ الصف الرابع الابتدائي. r-الحدود المكانية: مدرسة سيدة المحبة الآلهية بمحافظة دمياط.

\section{أورايت الهمبه}

أولاً: أدوات التجريب وتتشنمل علي:

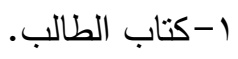

r- دليل المعلم لتدريس وحدتي ( في الثنارع - في الحديقة ) في ضوء استراتيجية النمذجة

$$
\text { والمحاكاة. }
$$

ثانياً: أدوات القياس وتتشنمل على:

- مقياس المهارات البيئية والذي تضمن ثلاث محاور وهي ( تحديد المشكلات البيئية، جمع

وتتظيم المعلومات، إيجاد الحلول البديلة للمشكلات ) .

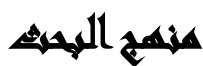

نم استخدام المنهج الوصفي لتحليل أهداف ومحتوى منهج اللغة الفرنسية القائم لمعرفة مدى توافر أهداف وموضوعات التربية البيئية فيه، كما نم استخدام المنهج شبه التجريبي في تجريب وحدتين دراسيتين على مجموعة من تلاميذ الصف الرابع الابتدائي بمدرسة سيدة

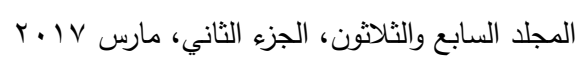


المحبة الآلهية بمحافظة دمياط، وذلك باستخدام التصميم التجريبي القائم على تصميم مجموعتين متكافئتين تجريبية وضابطة، واستخدام النطبيق القبلي والبعدي لأدوات البحث

$$
\text { المتمثلة في (مقياس المهارات البيئية). }
$$

\section{هروض المهيه}

$$
\text { سعى البحث إلى التحقق من الفرض الرئيسي التالي: }
$$

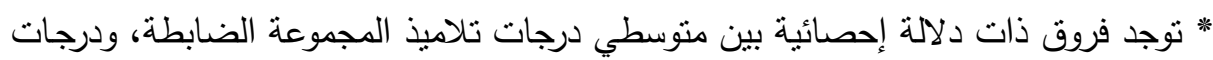
تلاميذ المجموعة التجريبية في مقياس المهارات البيئية قبل وبعد تطبيق الوحدنين المطورتين تندين

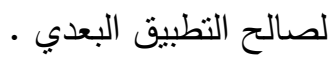

وتفرع عن الفرض الرئيسي الفروض البحثية التالية:

1 - توجد فروق ذات دلالـة إحصـائية بـين متوسطي درجـات تلاميـذ المجموعـة الضـابطة،

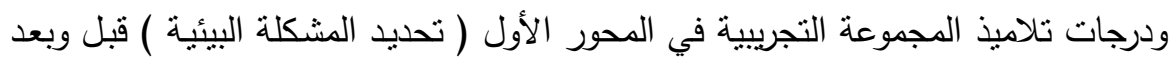

$$
\text { تطبيق المنهج لصالح التطبيق البعدي. }
$$

r- توجـد فروق ذات دلالمـة إحصـائية بـين متوسطي درجـات تلاميذ المجموعـة الضـابطة، ودرجات تلاميذ المجموعة التجريبية في المحور الثاني ( جمع وتتظيم المعلومات البيئية ) قبل وبعد تطبيق المنهج لصالح التطبيق البعدي.

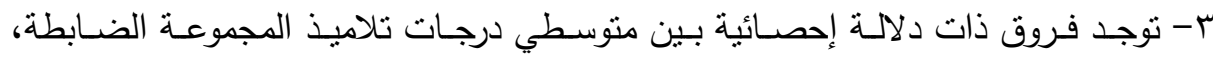

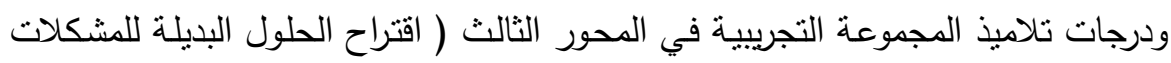
البيئية ) قبل وبعد تطبيق المنهج لصالح النطبيق البعدي.

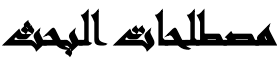

تطوير المنهج: هو "عملية نستهدف تتمية عناصر المنهج بدايةً من أهدافه، ومروراً بمحتواه وأساليب التدريس والوسائل التعليمية والأنشطة الدصاحبة وأساليب التقويم بغرض رفع كفاءة

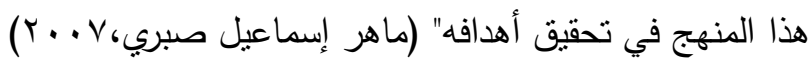

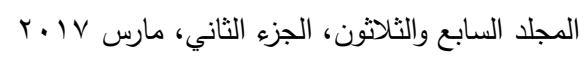


النمذجة: هي عملية تبسيط وتقليد لحدث أو ظاهرة نود فهمها بطريقة أفضل ( عبد الرازق

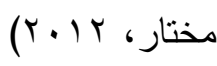

المحاكاة: هي طريقة أو أسلوب تعليمي يستخدمه المعلم عادة لنقريب الطلبة إلى العالم

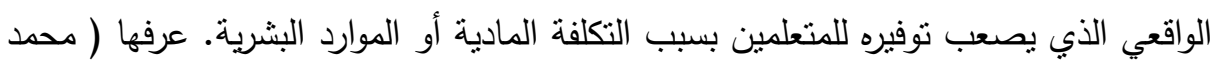
عبد الوكيل، . (r.) استراتيجية النمذجة والمحاكاة: خطة تدريس وتعلم يؤديها المعلم والمتعلم وفق خطوات النمذجة ذات العلاقة ببعض مهارات حل المشكلات البيئية المتضمنة، مع استخدام تمثيليات

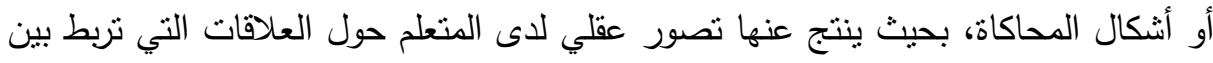

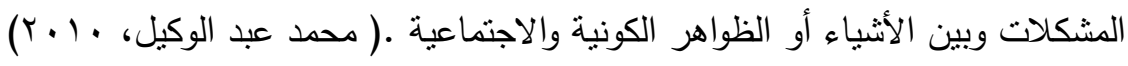

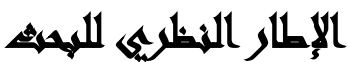

هذا وتمتل الإطار النظري للبحث ثلاث محاور رئيسية وهي: المحور الأول: نطوير المناهج الدراسية في ضوء أهداف التربية البيئية من حيث: (مفهوم المنهج ومفهوم التطوير / عوامل تطور المنهج / المنهج والتربية / فلسفة التربية البيئية). • المحور الثاني: التربية البيئية واللغة الفرنسية من حيث: (اللغة الفرنسية والحاجة إلى التربية

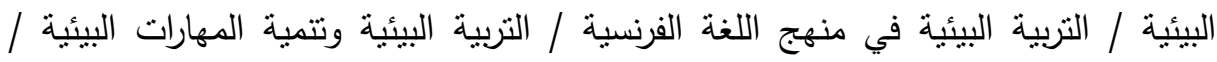
مداخل تضمين التربية البيئية في المناهج الدراسية / دور مناهج اللغة الفرنسية في تحقيق أهداف التربية البيئية ).

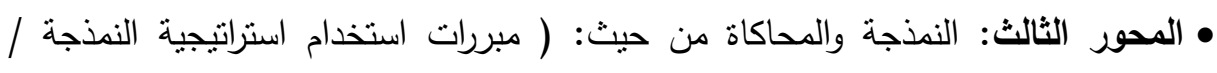

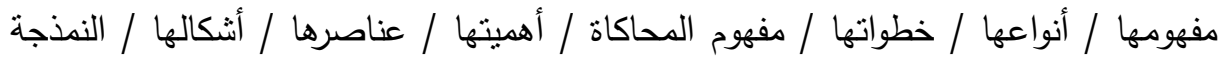

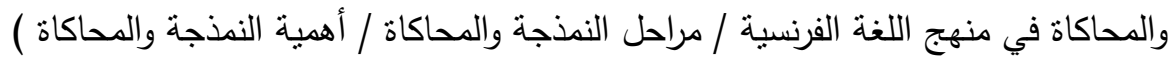




\section{إجراعاهـ المهمه}

أولاً: إعداد قائمة بأهم الموضوعات البيئية التي ينبغي أن يتضمنها مقرر اللغة الفرنسية باستخدام استراتيجية النمذجة والمحاكاة لتنمية المهارات البيئية لاى تلاميذ الصف الرابع

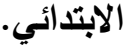

وللإجابة عن السؤال الأول للبحث: ما الموضوعات البيئية التي ينبغي أن يتضمنها مقرر اللغة الفرنسية باستخدام استراتيجية النمذجة والمحاكاة لتتمية المهارات البيئية لاى تلاديذ الصف الرابع الابتدائي؟

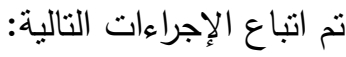
(1) تحديد الههف من وضع قائمة بأهم الموضوعات والمشكلات البيئية: هدفت القائمة إلي تحديد أهم الموضوعات والمشكلات البيئية والتي ينبغي أن يتضمنها مقرر اللغة الفرنسية

$$
\text { من حيث ( مفهومها - أسبابها - آثارها - دور الطالب في الحد منها ) }
$$

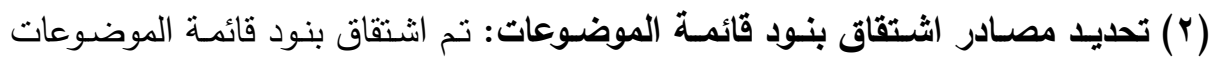

$$
\text { والمشكلات البيئية من خلال: }
$$

* الدراسات والبحوث السابقة التي تتاولت نطوير المناهج الدراسية في ضوء أهداف التربية

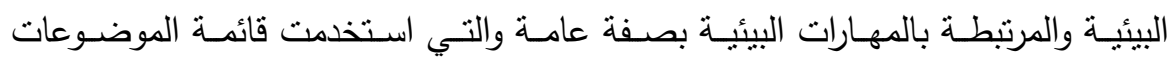

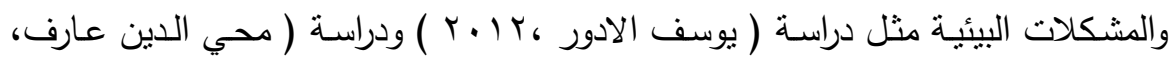

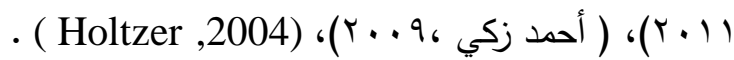
* الكتب والمراجع العلمية المتخصصـة التي تتاولت النمذجة والمحاكاة في المناهج الدراسية

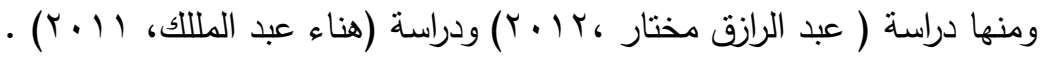

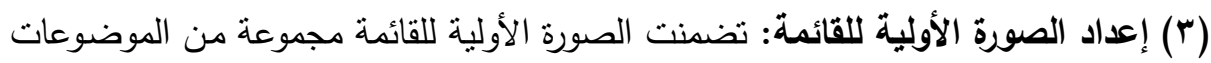

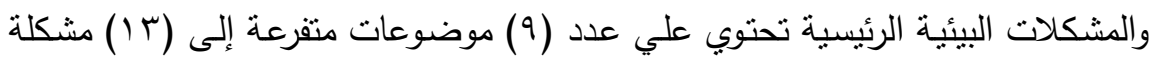
بيئية والتي يمكن تضمينها في مقرر اللغة الفرنسية لتلاميذ الصف الرابع الابتدائي .

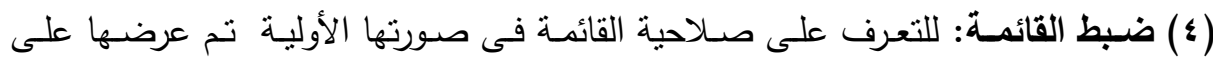
مجموعة من المحكمين وذللك للتعرف على آرائهم من حيث مدى: 


\section{رشا الخميسي وآخرون}

1- مناسبة تللك الموضـوعات الـواردة بالقائمـة بمقرر اللغـة الفرنسية لتلاميذ الصف الرابع - الابندائي

r-ملاعمة الموضوعات الواردة بالقائمة بمقرر اللغة الفرنسية لتلاميذ الصف الرابع الابتدائي.

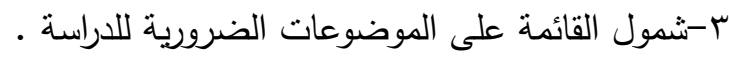
* وأبدوا مناسبتها وملاعمتها وشموليتها بمقرر اللغة الفرنسية لتلاميذ الصف الرابع الابتدائي.

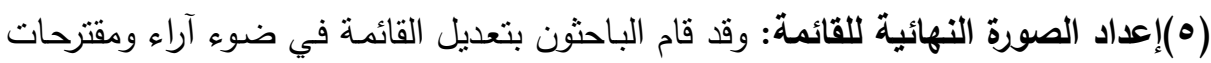

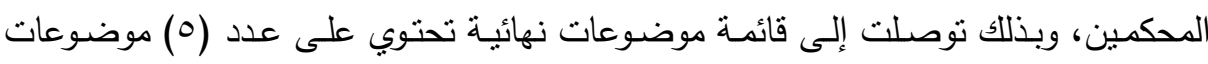
متفرعة إلى (9) مشكلة بيئية. ويوضـح شكل (1) الصـورة النهائيسة لقائمـة أهم الموضـوعات والششكلات البيئيـة والتي تضمنها مقرر اللغة الفرنسية لتلاميذ الصف الرابع الابتدائي. شكل(1): الصورة النهائية لقائمة أهم الموضوعات التي تضمنها مقرر اللغة الفرنسية لتلاميذ

$$
\text { الصف الرابع الابتدائي }
$$

\begin{tabular}{|c|c|}
\hline ما تضنذه الموضنوع & البيوضئوع \\
\hline 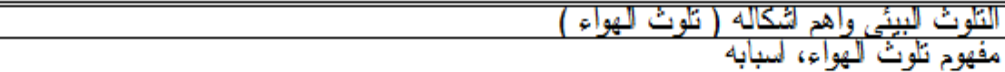 & \multirow[b]{2}{*}{ الثهواث: } \\
\hline 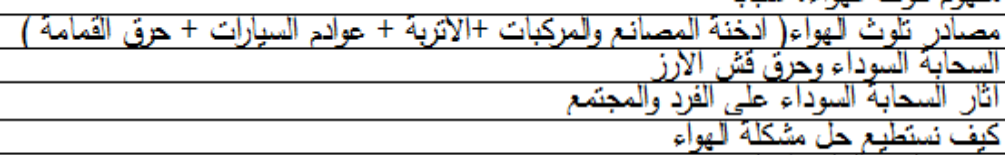 & \\
\hline 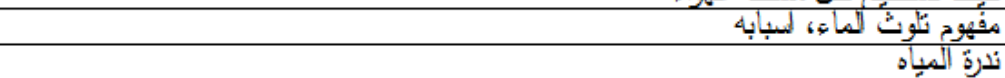 & الثلوثت \\
\hline 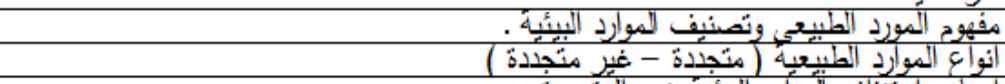 & \multirow{3}{*}{ المنتززاف } \\
\hline 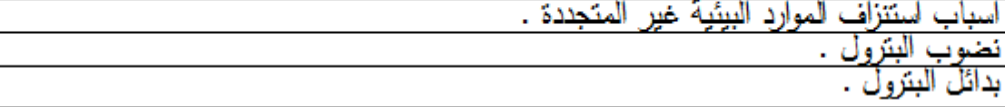 & \\
\hline 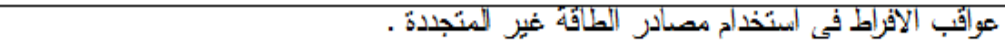 & \\
\hline 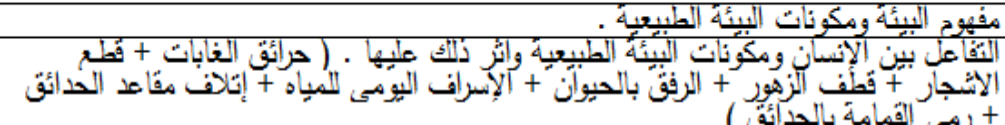 & \multirow{2}{*}{ التصحز } \\
\hline 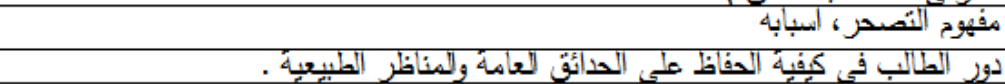 & \\
\hline
\end{tabular}

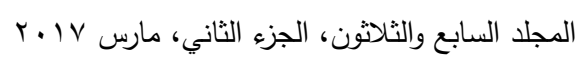


ثانياً : إعداد منهج مقترح لتنمية المهارات البيئية لاى تلاميذ الصف الرابع الابتائي

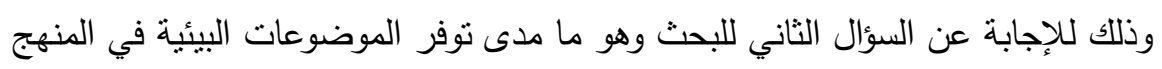

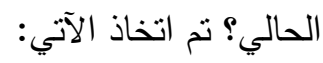

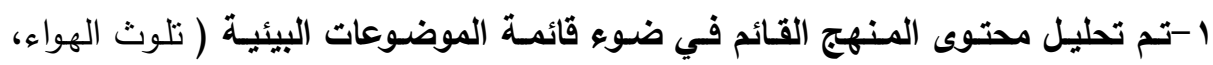
استنزاف الموارد غير المتجددة ونضـوب البترول، وتلوث المياه، التصحر ، ندرة المياه ) حيث وجد قصور المنهج القائم في تتاول جوانب التربية البيئية وتحقيق أهدافها.

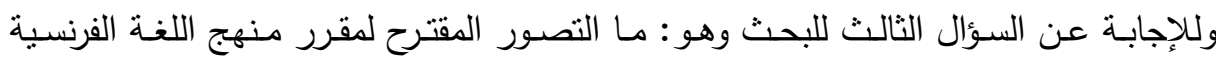

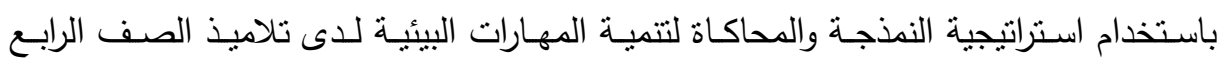

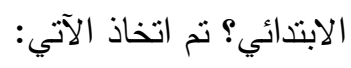
1- وضـع إطـار عـام للتصـور المقترح لمنهج اللغـة الفرنسية باستخدام استراتيجية النمذجـة

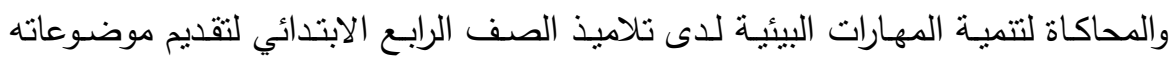

$$
\begin{aligned}
& \text { ويشمل: }
\end{aligned}
$$

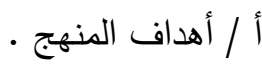

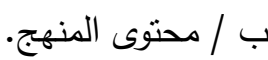

$$
\begin{aligned}
& \text { ج / توزيع مقترح لموضوعات إطار المنهج. } \\
& \text { د / الوسائل التعليمية للمنهج _ الأنشطة _ الأساليب واستراتيجيات التدريس. } \\
& \text { هـ / تقويم المنهج. }
\end{aligned}
$$

ويوضح شكل (Y) الصورة النهائية لمنهج اللغة الفرنسية المقترح القائم على استراتيجية النمذجة والمحاكاة لتتمية المهارات البيئية لدى تلاميذ الصف الرابع الابتدائي. 
رشا الخميسي وآخرون

شكل(ץ): الصورة النهائية لمنهج اللغة الفرنسية المقترح القائم على استراتيجية النمذجة

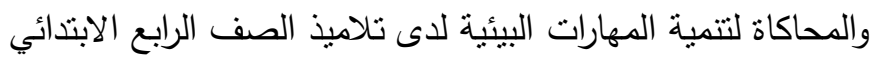

\begin{tabular}{|c|c|c|c|c|c|c|}
\hline لتئكوب & الأنشطة للتبتبة لتنفيذ & 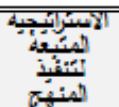 & لمتمبري & 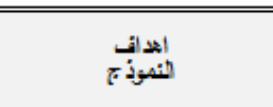 & 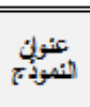 & لبيئينو \\
\hline 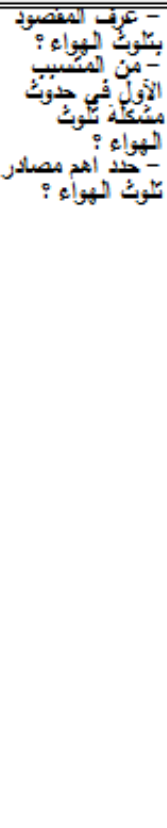 & 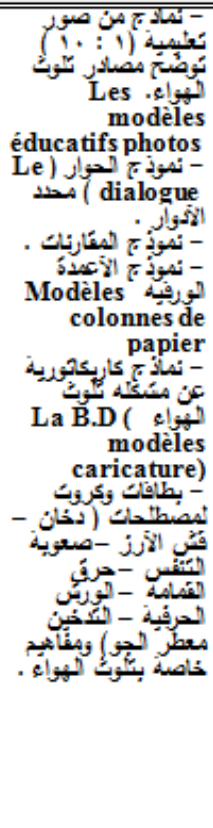 & 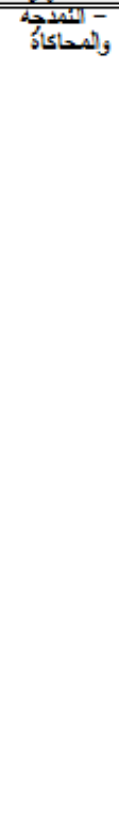 & 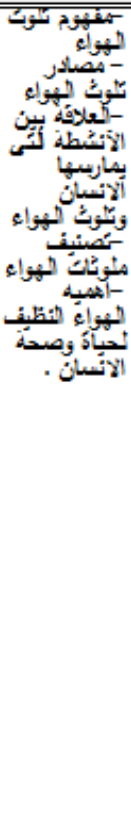 & 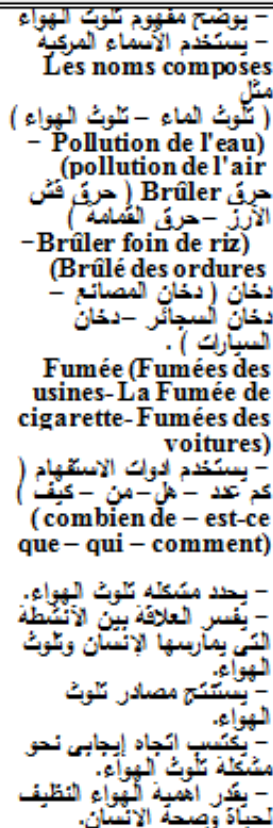 & 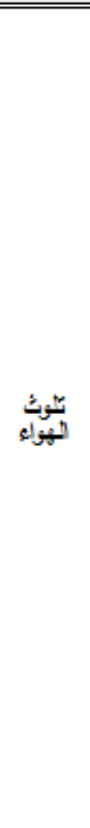 & (1) \\
\hline 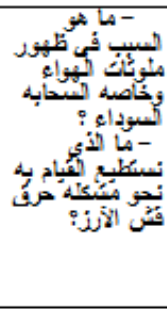 & 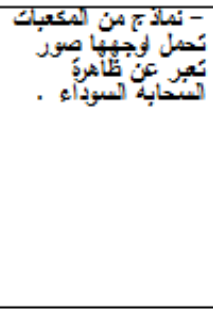 & والمحاكأَة & 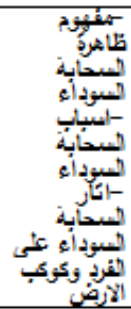 & 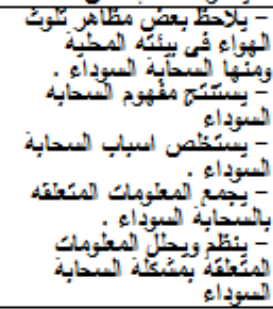 & لستوأبة & (ץ) \\
\hline
\end{tabular}


تايع: شكل(ץ): الصورة النهائية لمنهج اللغة الفرنسية المقترح القائم على استراتيجية النمذجة والمحاكاة لتتمية المهارات البيئية لدى تلاميذ الصف الرابع الابتدائي

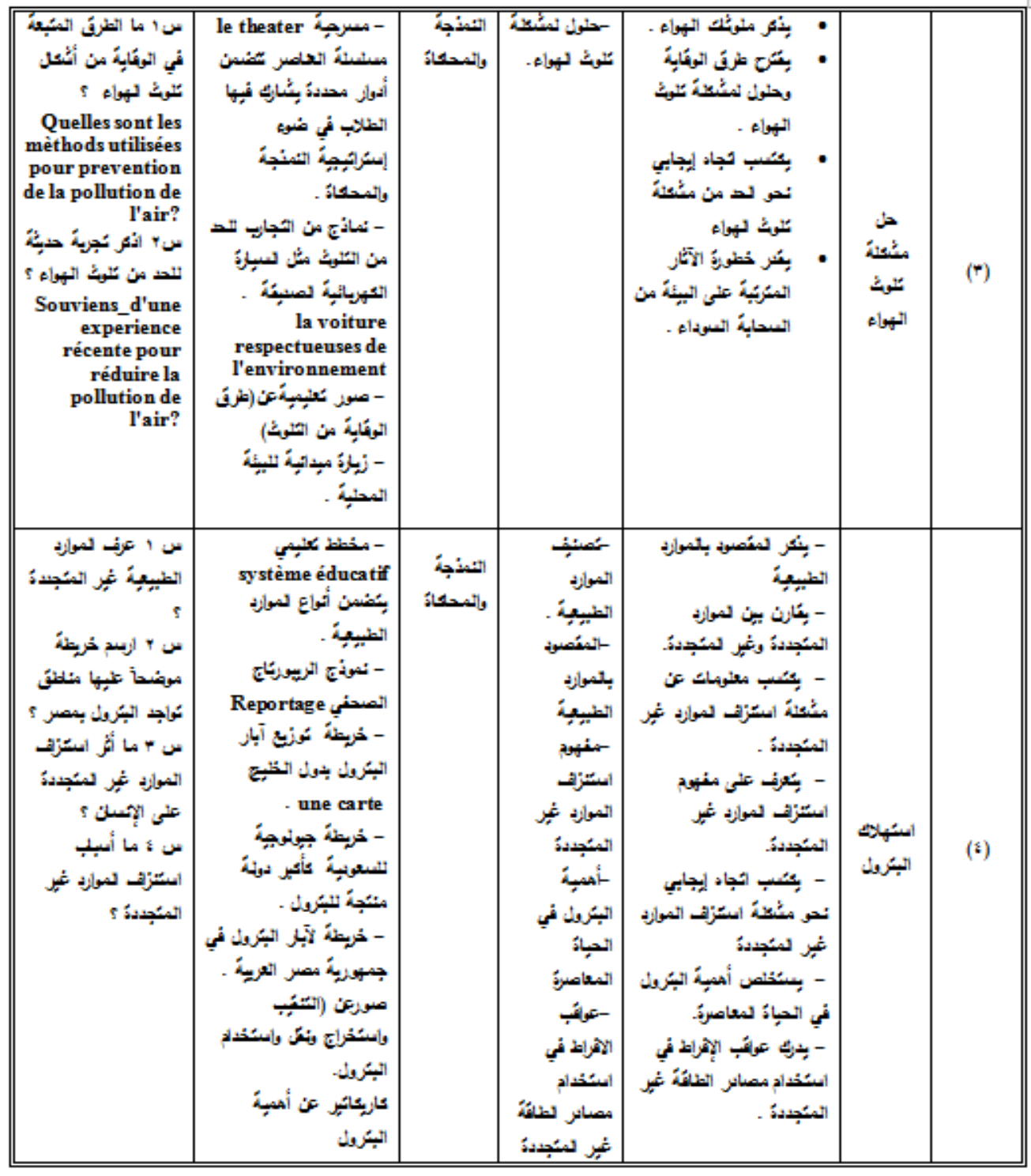


تابع: شكل(ץ): الصورة النهائية لمنهج اللغة الفرنسية المقترح القائم على استراتيجية النمذجة والمحاكاة لتتمية المهارات البيئية لدى تلاميذ الصف الرابع الابتدائي

\begin{tabular}{|c|c|c|c|c|c|c|}
\hline 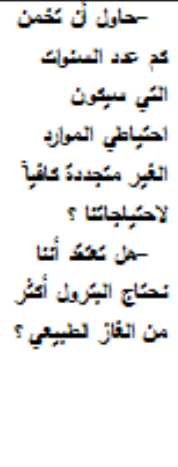 & 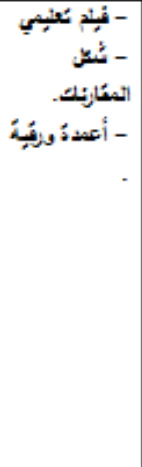 & أنمحسكاءة & 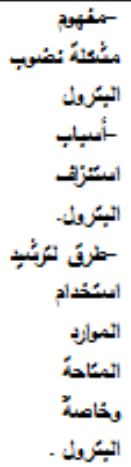 & 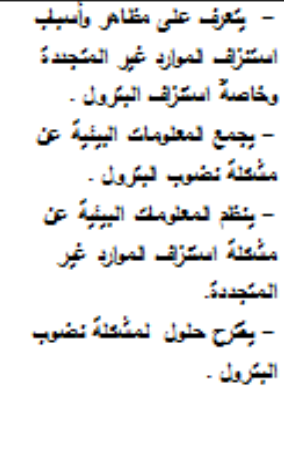 & 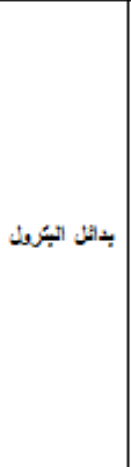 & () \\
\hline 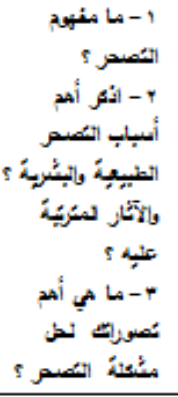 & 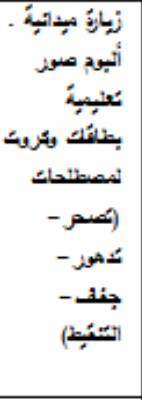 & النمحنجة: & 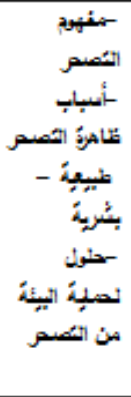 & 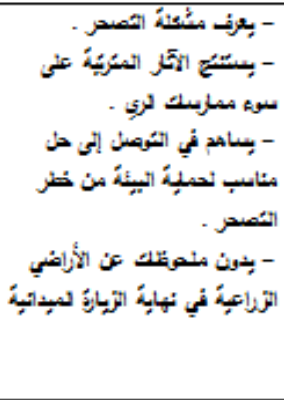 & مئر & (ฯ) \\
\hline 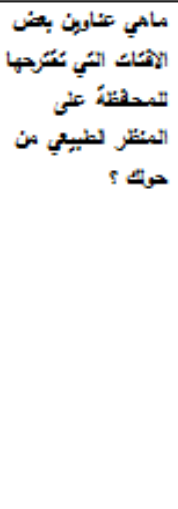 & 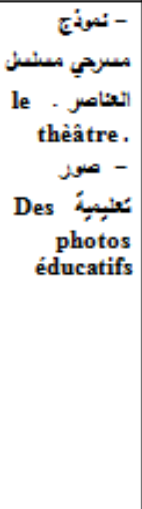 & النمحنَّة: & 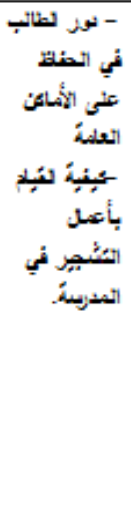 & 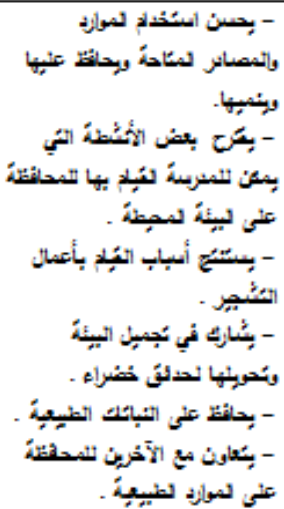 & 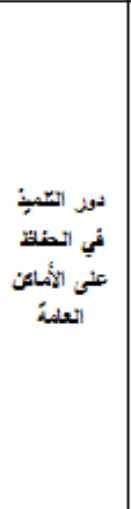 & (v) \\
\hline
\end{tabular}


مجلة العلوم البيئية

معهز الدراسات والبحوث البيئية - جامعة عين شمس لهن

تابع: شكل(ץ): الصورة النهائية لمنهج اللغة الفرنسية المقترح القائم على استراتيجية النمذجة والمحاكاة لتتمية المهارات البيئية لدى تلاميذ الصف الرابع الابتدائي

\begin{tabular}{|c|c|c|c|c|c|c|}
\hline 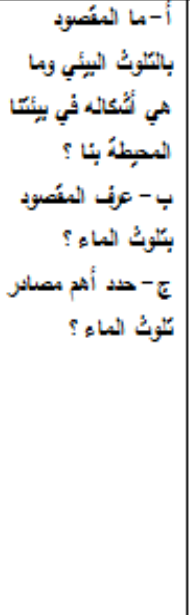 & 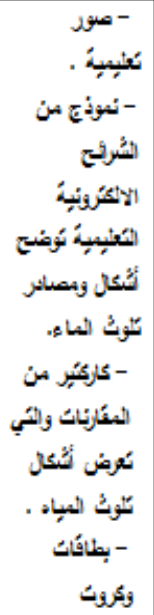 & وألمحاكاءة & 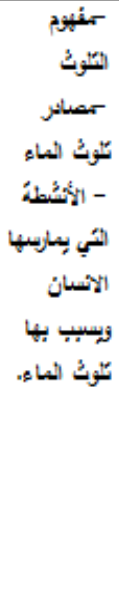 & 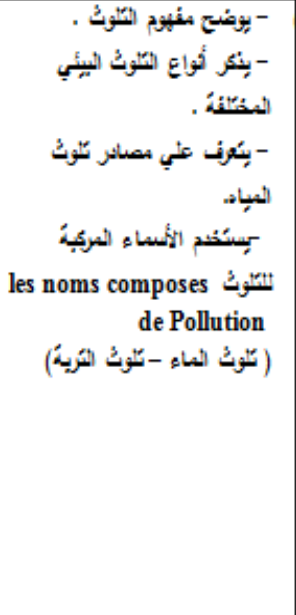 & تلويُ3 الشاء & (^) \\
\hline 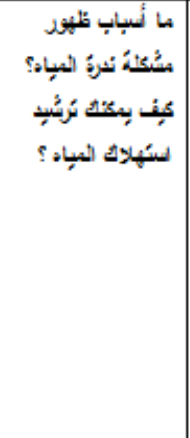 & 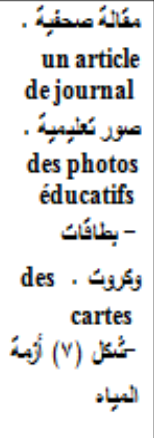 & والمحاكائ & 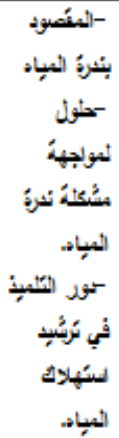 & 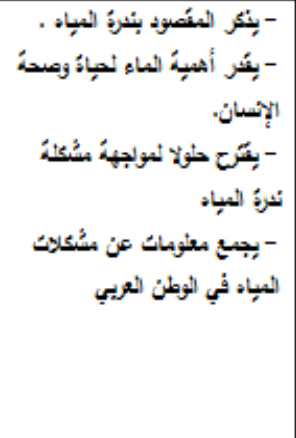 & نثرةٌ المباء & (9) \\
\hline
\end{tabular}


ثالثاً : إعداد مقياس المهارات البيئية

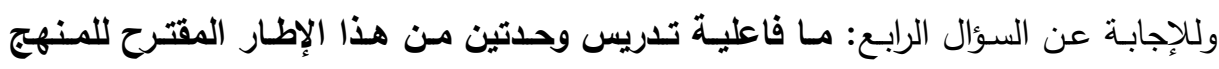

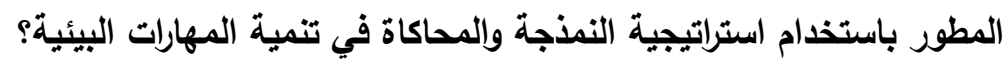

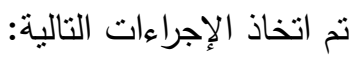
* تحديد هدف المقياس: يهدف إلى تتمية المهارات البيئية بعد تدريس الوحدنين الدراسيتين

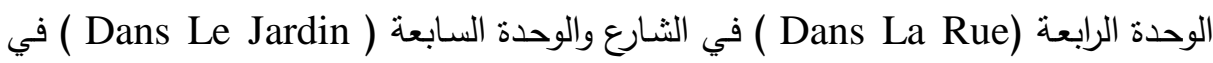
الحديقة بمنهج اللغة الفرنسية للصف الرابع الابتدائي مجموعة البحث ( التجريبية) من حيث

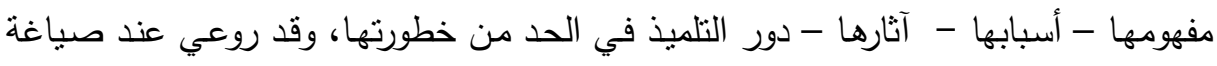
مفردات المقياس ارتباط الأسئلة بقياس المهارات البيئية التي حددها الباحثون، مرونة الأسئلة

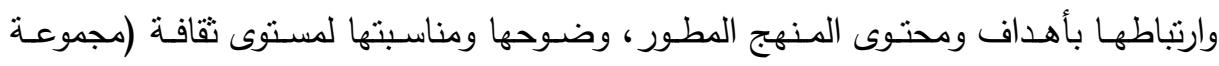
البحث) • واحتوى المقياس في صورته الأولية علي خمسة من أهم الموضوعات البيئية التي ولي لئي

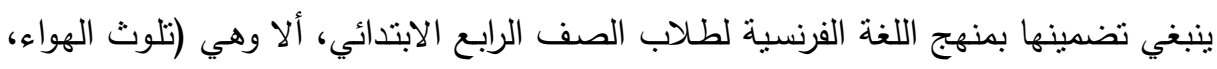

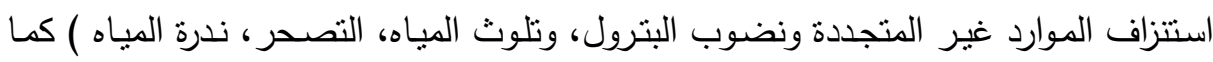
احتوي المقياس علي ثلاثة محساور والتي تضـنت تللك الموضـوعات البيئية وهي ( تحديد

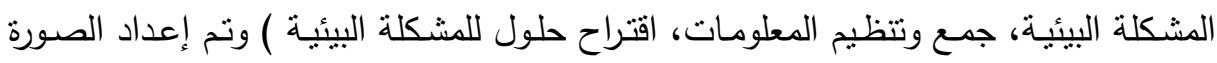

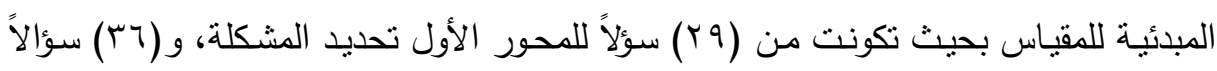

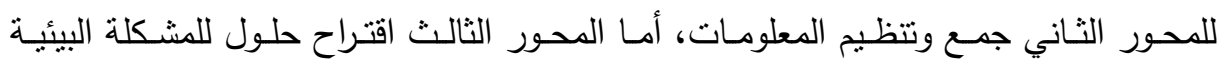

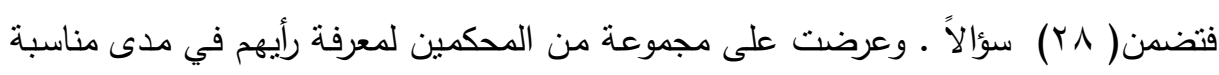

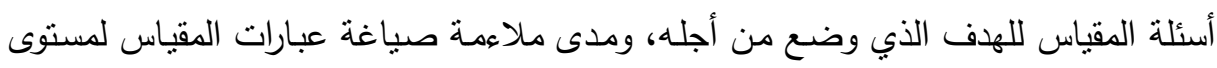

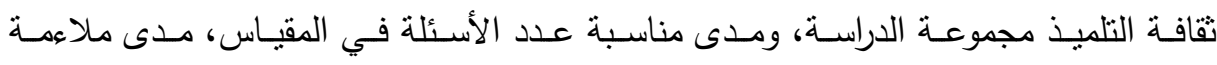

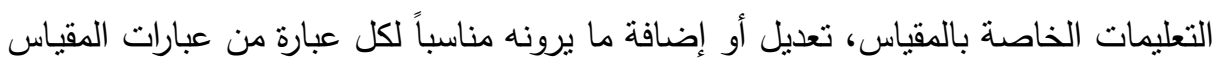

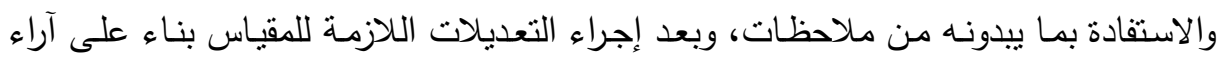
المحكمين، قام الباحثون بتجربة المقياس على مجموعة من تلاميذ مدرسة سيدة المحبة الآلمية

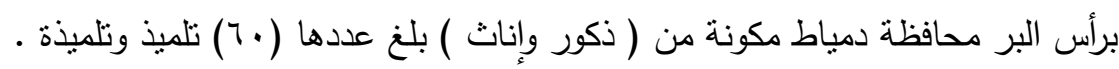

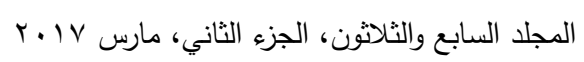


لتعديل المقياس في ضوء ما تسفر عنه التجربة الاسنطلاعية تم تحديد زمن وثبات المقياس.

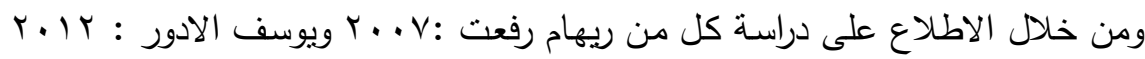

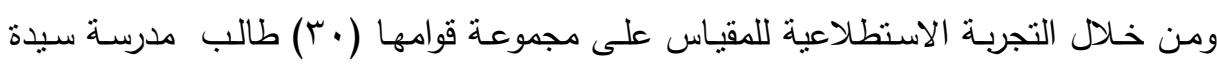

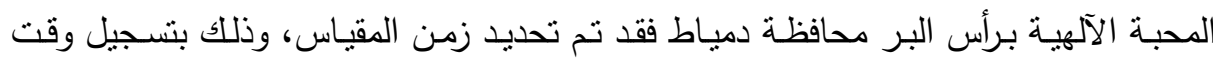
البداية للإجابة على المقياس ثم حسب الزمن الذي استغرق فى الإجابة على مفردات المقياس

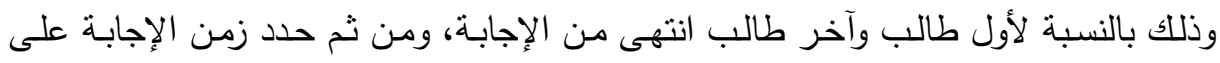
المقياس وفقاً للمعادلة التالية:

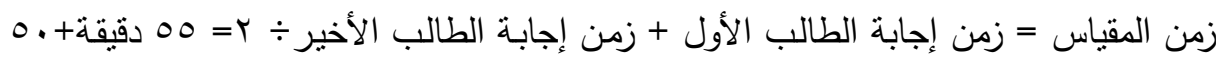

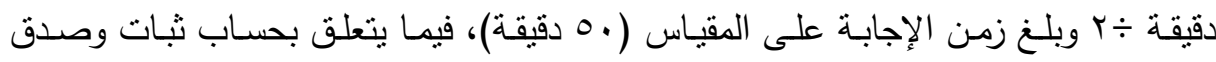

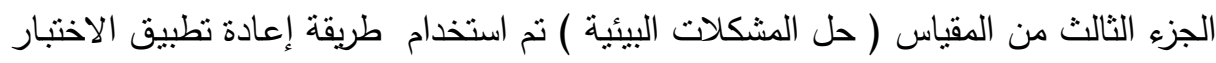

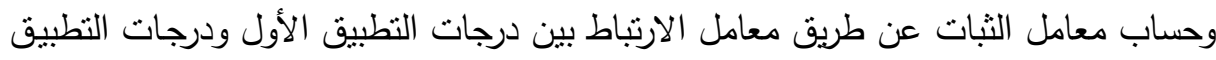

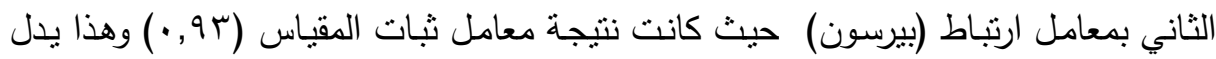

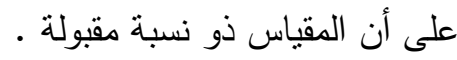

وللتحقق من صدق الاختبار استخدم الباحثون ( الصدق الذاتي وهو الصدق المتعلق بالمظهر العام للمقياس من حيث مدى وضوح المفردات، وتعليمات المقياس، وموضوعيتها، ومدى مناسبته للتلميذ وتأكد الباحثون من كل ما سبق من خلام الأخذ بآراء السادة المحكمين

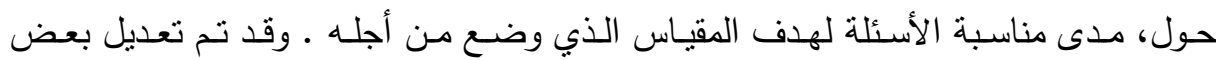
مفرداته، وأصبح في صورته النهائية حيث شمل ثنلاث محاور رئيسية وهي مهارة ( تحديد

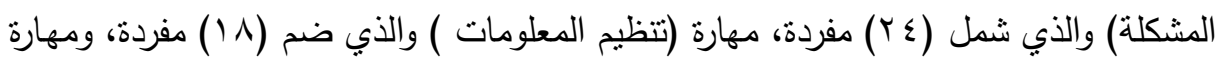
( ايجاد الحلول البديلة ) حيث شمل (• ب) مفردة وقد وزعت المشكلات البيئية علي الأسئلة التي يتكون منها المقياس ثم طرحت بطريقة عشوائية على بنود المقياس. ويوضح جدول (r): جدول مواصفات مقياس المهارات البيئية في شكله النهائي. 
رشا الخميسي وآخرون

جدول(r): يوضح محاور مقياس المهارات البيئية

\begin{tabular}{|c|c|c|c|}
\hline الارجات الكلية & عدد المفردات & المهارة التى يقيسها & المحور \\
\hline$r \leq$ & $r \varepsilon$ & تحديد المشكلة البيئية & الآول \\
\hline ry & 11 & تتظيم المعلومات والبيانات & الثناني \\
\hline$\varepsilon$. & r. & اقتراح الحلول البديلة & الثالث \\
\hline $1 \cdots$ & $T Y$ & & المجموع \\
\hline
\end{tabular}

ولتقدير درجات المقياس كان على النحو التالي:

أولاً: المحور الأول (تحديد المشكلة )

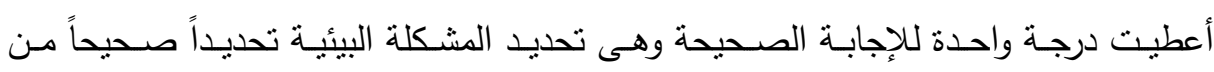
المجموع الكلي (ع Y) بينما تعطى صفراً للإجابة الخاطئة . ثانياً: المحور الثانى ( تنظيم المعلومات ) أعطيت درجتان عن كل عبارة توضع فى مكانها الصحيح أمام المشكلة التى تتعلق بها من المجموع الكلي (דr) ويعطى (صفر) للإجابة الخاطئة .

ثالثاً: المحور الثالث ( ايجاد الحلول البديلة)

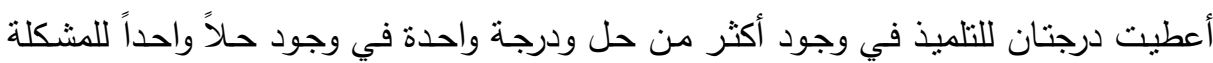

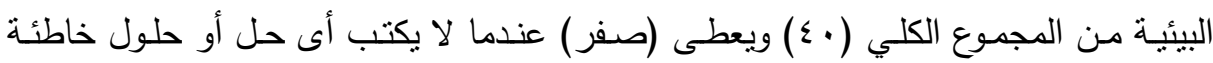
للمشكلة البيئية

\section{إجراعايت الصراسة الميشانية}

1 - اختيار مجموعة البحث: تم تطبيق المنهج المطور القائم على استراتيجية النمذجة والمحاكاة على مجموعة من تلاميذ الصف الرابع الابتدائي قوامها (·r) بمدرسة سيدة

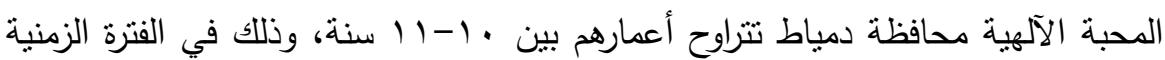
من

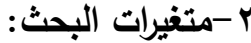

المتغير المستقل: المنهج المطور ممثلا في (الوحدتين الدراسيتين). المتغيرات التابعة: تتمية ( المهارات البيئية). 


\section{* إجراءات تطبيق مقياس المهارات البيئية:}

1- تم تطبيق المقياس قبلياً على مجموعة البحث ( الضابطة )، و ( التجريبية ) .وذلك في

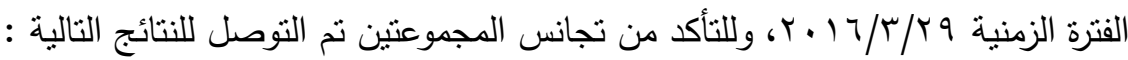
جلول(؛): المتوسط والانحراف المعياري وقيمة (ت) لنتائج النطبيق القبلي ( مقياس المهارات

البيئية )

\begin{tabular}{|c|c|c|c|c|c|c|c|}
\hline \multirow{2}{*}{ مستد مستوية } & \multirow[b]{2}{*}{ قتيمة } & \multirow[b]{2}{*}{ قفيمة } & \multicolumn{2}{|c|}{ 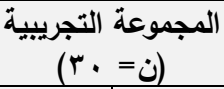 } & \multicolumn{2}{|c|}{ 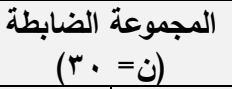 } & \multirow[b]{2}{*}{ مقياس المهارات البيئية } \\
\hline & & & المعياري & المتوسط & المعياري & المتوسط & \\
\hline غير دال & $1, \curlyvee \wedge \mathrm{V}$ & $1, \leqslant 94$ & $1, \mu_{0}$ & $\vee, \uparrow \wedge$ & 1,94 & 7,90 & المشكور الأول: إدراك وتحليد \\
\hline غير دال & $1,0 . r$ & זי4., & $r, Y r$ & ד, & $r, r r$ & $\bullet, \vee \wedge$ & وتحليل المعلومات البيائية الثئيم \\
\hline غير دال & $1,1 \times 4$ & $\cdot, \cdots 4$ & 1,09 & $\varepsilon, V \mu$ & 1,09 & $\varepsilon, r V$ & لحل المشكلات البيئية الثقالث حلول \\
\hline غير دال & $1,9 \leqslant 1$ &.,$\leqslant 9$. & $r, V r$ & $M \Lambda, V Y$ & $\{, 10$ & $17, \mathrm{Vr}$ & الدرجة الكلية \\
\hline
\end{tabular}

r- ثم تدريس المنهج المطور القائم على استراتيجية النمذجة والمحاكاة على المجموعة التجريبية .

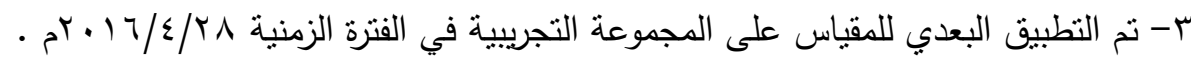
بعد الانتهاء من تطبيق المنهج المطور ممثلا في (الوحدنين الدراسيتين) القائم على استراتيجية

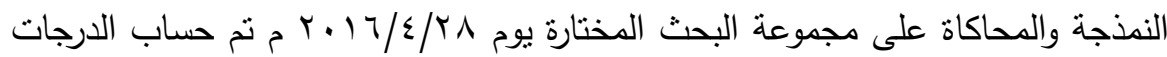
ورصدها في جداول أعدت لهذا الغرض. 


\section{**رصد النتائج ومعالجتها إحصائياً:}

أولاً : للتحقق من صحة الفرض الأول:

وهو" توجد فروق ذو دلالة إحصائية بين منوسطي درجات تلاميذ المجموعة الضابطة ودرجات تلاميذ المجموعة التجريبية، وذلك بالنسبة لمقياس المهارات البيئية في التطبيق البعدي لصالح

$$
\text { المجموعة التجريبية التي درست الوحدتين". }
$$

وتبين من جدول (0) نتائج اختبار (ت) لحساب دلالة الفروق بين منوسطي درجات تلاميذ المجموعة الضابطة ودرجات تلاميذ المجموعة التجريبية، وذلك بالنسبة لمقياس المهارات البيئية في التطبيق البعدي لصالح المجموعة التجريبية التي درست الوحدتين". جدول(ه): المتوسط والانحراف المعياري وقيمة (ت) لنتائج النطبيق البعدي ( مقياس المهارات

البيئية )

\begin{tabular}{|c|c|c|c|c|c|c|}
\hline \multirow{2}{*}{ مستوى 1 مند مستوى 1 معتية } & \multirow[b]{2}{*}{ قيمة } & \multicolumn{2}{|c|}{ 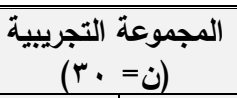 } & \multicolumn{2}{|c|}{ 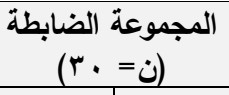 } & \multirow[b]{2}{*}{ مقياس المهارات البيئية } \\
\hline & & الانحراف & المتوبط & الانحراف & المتوسط & \\
\hline دالة & $r \wedge, \wedge r$ & $1, \wedge 1$ & $r q, r r$ & $r, Y q$ & $0,7 V$ & المشكور الأول: إدرالك وتحديد \\
\hline دالة & rq,7० & $r, 10$ & $r q, \wedge r$ & 1,70 & $\leq, 1$. & والمحور الثاني: جمع وتنظيم المعلئية \\
\hline دالة & $r v, 04$ & $r, \cdot r$ & $r \cdot, \leqslant \Lambda$ & $1, \leqslant 1$ & r,or & المشكور الثالث: إقتراح حلول لحل \\
\hline دالة & $07,1 \leq$ & $\varepsilon, \wedge r$ & VY,Or & $r, \wedge r$ & Ir,r. & الدرجة الكلية للمقياس \\
\hline
\end{tabular}

تبين من خلال جدول (0) أن متوسط درجات مجموعة البحث على التوالى وذلك بالنسبة لمحاور مقياس المهارات البيئية (تحديد المشكلات البيئية- جمع وتتظيم وتحليل المعلوماتاقتراح الحلول البديلة ) فى النطبيق البعدى وهو ما يؤدى الى قبول الفرض توجد فروق ذات

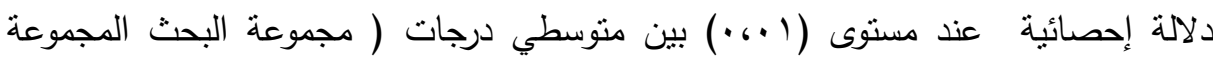
التجريبية ) في مقياس المهارات البيئية قبل وبعد تطبيق المنهج لصالح النطبيق البعدي. 
ولحسـاب فاعليـة المنهج المطور الممثل في وحدنين دراسيتين في تتميـة المهارات البيئيـة لتلاميذ الصف الرابع الابتدائي تم حساب نسبة الكسب المعدل ويوضسح جدول (؟) نسبة الكسب المعدل للمنهج. جدول(7): يوضح نسبة الكسب المعدل (معادلة بلاك)

\begin{tabular}{|c|c|c|c|c|c|}
\hline \multirow{2}{*}{ مستوى } & \multirow{2}{*}{ نسبة الكسب } & \multicolumn{2}{|c|}{ متلوسط درجات الطالبات } & \multirow{2}{*}{ الالكلية } & \multirow{2}{*}{ مقياس المهارات البيئية } \\
\hline & & البطبيق & التطبيق & & \\
\hline مرتفع & 1,1 & rq,Yr & $v, \uparrow \wedge$ & $r \leqslant$ & البيئةية الأول: إدراك وتحديد المشكلات \\
\hline مرتفع & 1,7 & $r q, \Lambda r$ & ד, & rq & المطلومات الثائية: جمع وتنظيم وتحليل \\
\hline مقبول & 1,1 & $r \cdot, \leqslant \Lambda$ & $\varepsilon, V r$ & ؛. & المشكورت البثالثية: إقتراح حلول لحل \\
\hline مرتفع & 1,0 & V4,Or & $I \Lambda, V Y$ & $1 \ldots$ & الارجة الكلية للمقياس \\
\hline
\end{tabular}

ويتضح من جدول (7) أن نسبة الكسب المعدل لبلاك كانت نتائجه على النحو التالي: أولاً: مقياس المهارات البيئية وكانت نسبة الكسب المعدل في المهارة الأولى لونى (تحديد المشكلات ) (1, (1)، بينما كانت نسبة الكسب المعدل في المهارة الثانية

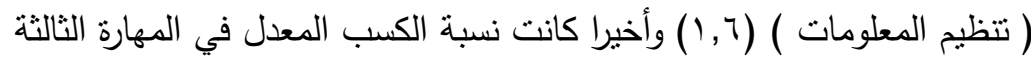

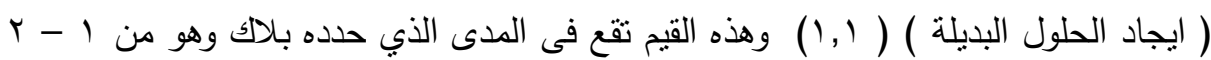
وتدل هذه القيم على أن المنهج المطور الممنل في الوحدتين الدراسيتين ذو فعالية في تتمية المهارات البيئية . وللتعرف على حجم تأثثير المنهج المطور واستراتيجية تدريسه ( النمذجة والمحاكاة )، نم إيجاد مربع آيتا كما هو مبين بجدول هبم ناينر (v) 
رشا الخميسي وآخرون

جدول(V): يبين حجم تأثثر الاستراتيجية المقترحة ( النمذجة والمحاكاة) فى نتمية المهارات البيئية:

\begin{tabular}{|c|c|c|c|}
\hline مقدار حجم & قيمة مربع & المتفير التابع & المتغير المستقل \\
\hline كبير &., 91 & المهارات البيئية & الوحتتين القائمتين على النمذجة والمحاكاة \\
\hline
\end{tabular}

يتبين من جدول (V) أن حجم تأثثر المنهج المطور واستراتيجية ندريسه ( النمذجة

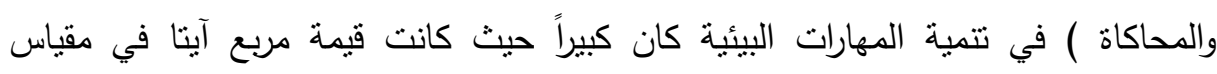

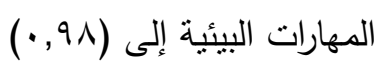

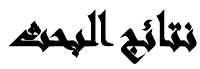

أثنارت النتائج المستخلصة بعد تطبيق المنهج المطور الممنل في الوحدتين الدراسينين

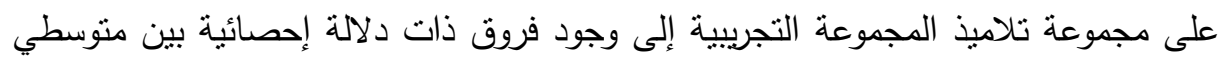
درجات تلاميذ المجموعة الضابطة ودرجات تلاميذ المجموعة التجريبية في مقياس المهارات البيئية قبل وبعد نطبيق المنهج لصالح التطبيق البعدي، وهذه النتيجة نوضح فعالية المنهج المطور واستراتيجية تدريسه ( النمذجة والمحاكاة ) في تتمية المهارات البيئية لدى لدى تلاميذ الصف الرابع الابتدائي ، وبالإمكان تفسير تفوق المجموعة التجريبية في المقياس البعدي إلى فئل

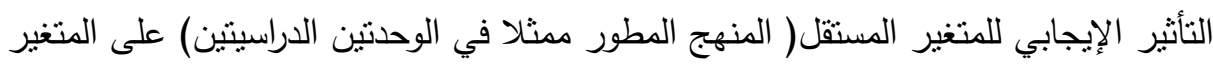
التابع (المهارات البيئية)، وذلك للأسباب التالية.

1- ارتفاع متوسط درجات مجموعة البحث ( المجموعة التجريبية ) في التطبيق البعدي

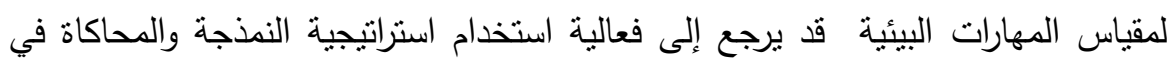
تتمية المهارات البيئية لتلاميذ الصف الرابع الابتدائي حول موضوعات البيئة التي نتاولها

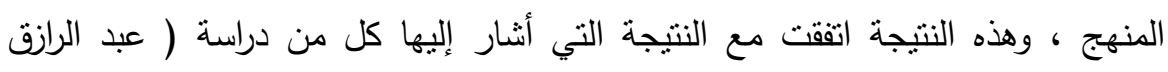
مختار r Y • Y) ودراسة (Heather,1999). 
حيث اتضح أن استخدام استراتيجية النمذجة والمحاكاة في التدريس ساعد التلميذ على

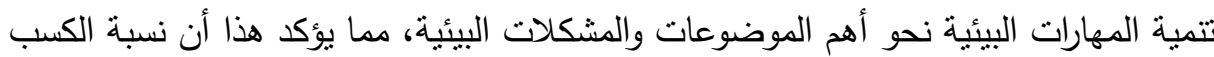

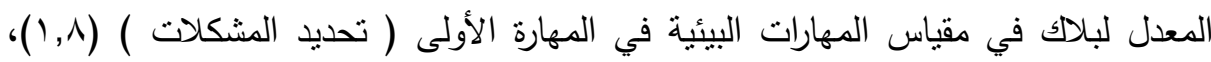
وكذلك كانت نسبة الكسب المعدل في المهارة الثانية ( تنظيم المعلومات ) (7, ( ) وأيضاً كانت

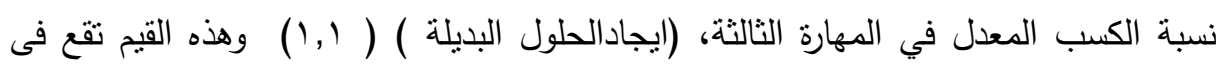

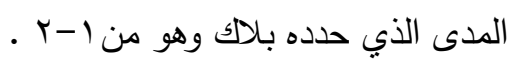

r- أن حجم تأثثر المنهج المطور المتمنل في الوحدنين الدراسيتين في تتمية المهارات البيئية كان كبيراً حيث بلغت قيمة مربع آيتا في مقياس المهارات البيئية إلى (بوه, •) وهي قيمة مناسبة تسهح بقبول هذا القدر من التأثثر، خاصة وأن منوسطي درجات مقياس

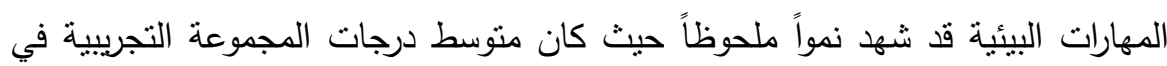

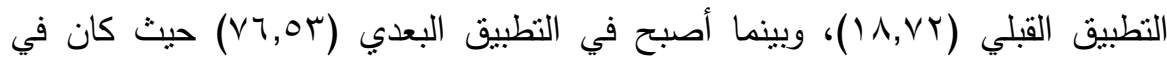

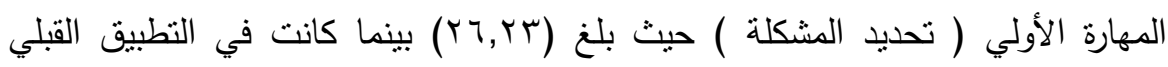

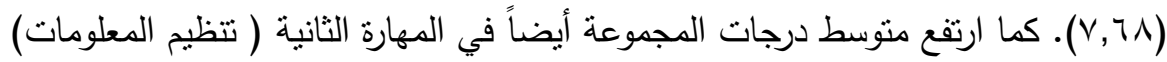

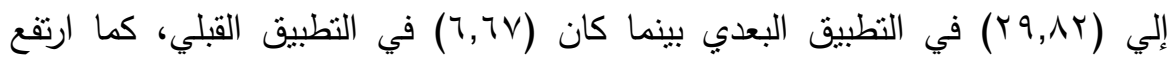
متوسط درجات المجموعة التجريبية ارتفاع ملحوظاً في المهارة الثالثة

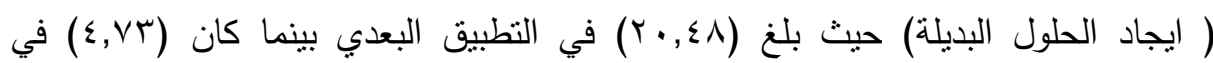

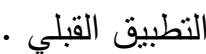
r- قد يرجع فاعلية المنهج المطور المتمثل في الوحدتين الدراسيتين فى نتمية المهارات البيئية لاى تلاميذ الصف الرابع الابتدائي الى تتوع النماذج المستخدمة أثتاء تدريس المنهج

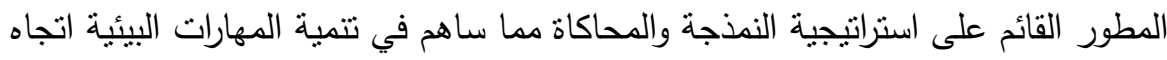
موضوعات (تلوث الهواء، السحابة السوداء، استتزاف الموارد غير المتجددة ونضوب

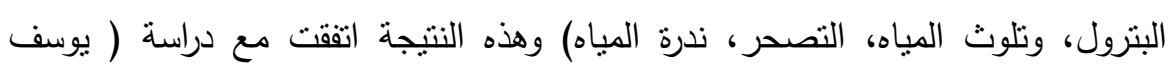

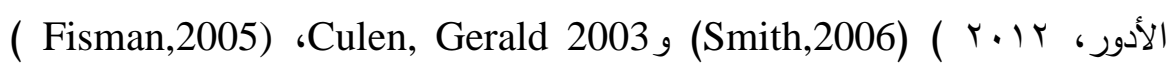
والتي أشناروا فيها على أن استخدام استراتيجيات متعددة في تدريس المهارات البيئية ومنها 
رشا الخميسي وآخرون

استراتيجية التعلم التعاوني والمناقشة وأسلوب حل المشكلات، تساعد في تتمية السلوك الايجابي نحو المحافظة على البيئة.

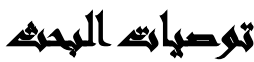

في ضوء النتائج التي أسفر عنها البحث يمكن تقديم مجموعة من التوصيات أهمها: - أهمية تطبيق المنهج المطور في هذه الدراسة على الطلاب بجميع المراحل التعليمية.

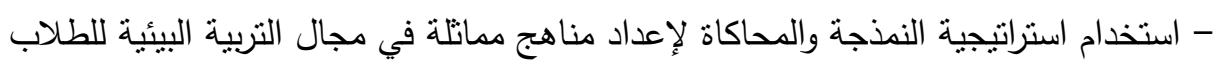
على أساس واقعي من دراسة الاحتياجات الفعلية لمتطلبات العصر الحديث، لتوعية

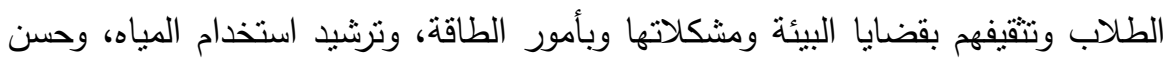
استخدام موارد الطاقة والمياه، مع الاهتمام بالأدوار الفعلية التي تمارسها المناهج في ونئي

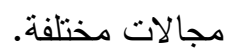

- تدريب معلمي اللغة الفرنسية على تدريس القضايا البيئية باستخدام استراتيجية النمذجة

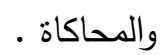

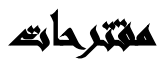

في ضوء ما توصلت إليه هذه الدراسة يمكن تقديم مجموعة من المقترحات من أهمها: استخدام استراتيجيات جديدة لتتمية المهارات البيئية والوعى البيئى في مناهج اللغات.

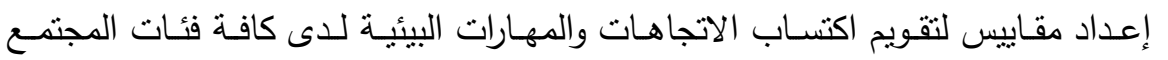

(نساء_شباب _ أطفال ) على مختلف المستويات (المهنية، الثقافية، العمرية ).

\section{zall}

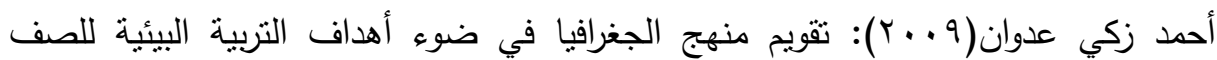

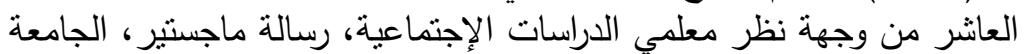

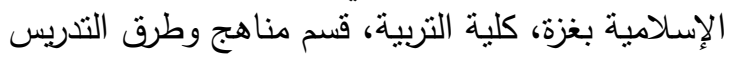

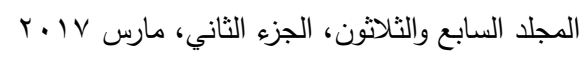


أكرم محمد صبحي العزاوي(V +. †): التربية البيئية بين المناهج والتطبيق، دار جامعة ذمار

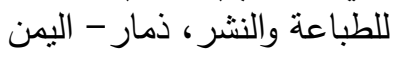

حنان حلمي ويصا(ب99 (1)): المهارات اللغوية لمنهج اللغنة الفرينة الفرنسية وتقويم دليل المعلم، دراسة تحليلية، كلية التربية، جامعة عين شمس المسار

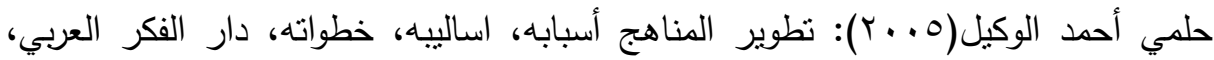

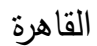

رياض الجبان(99V (19): التربية البيئية مشكلات وحلول، دار الفكر ، دمشق

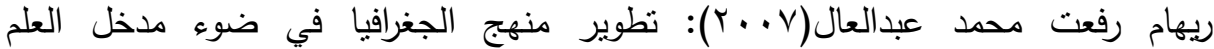

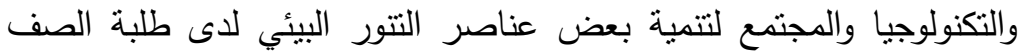

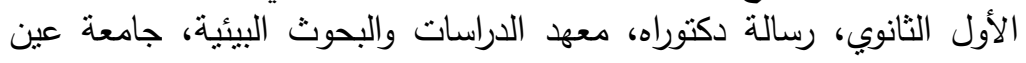

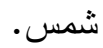

زين الدين عبد المقصود غنيمي( (. ب): قضايا بيئية معاصرة، المواجهة والمصالحة بين الإنسان والبيئة، منشأة المعارف، الإسكندرية.

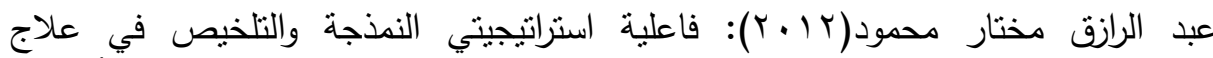

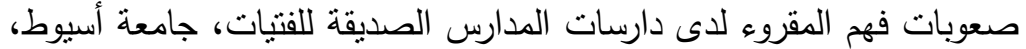

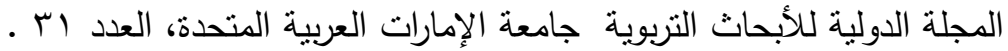

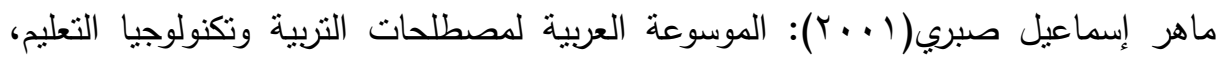

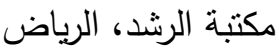

محمود أحمد حميد(r . .r): الثقافة البيئية مطلب حضاري للأسرة، سلسلة محاضرات، دار

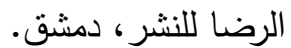

محمد صابر سليم(999 ()): مرجع في التربية البيئية، رئاسة مجلس الوزراء، جهاز شئون

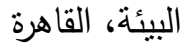

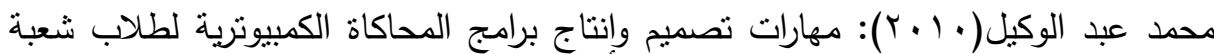

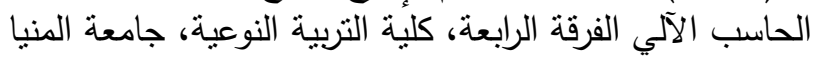

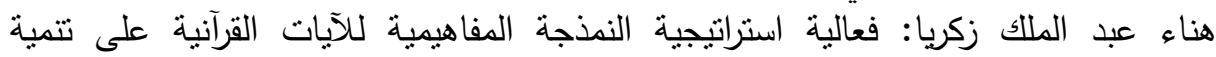
عمليات العلم في تدريس النظرية الذرية الحديثة بمنهج الكيمياء للصف الصفية الأول

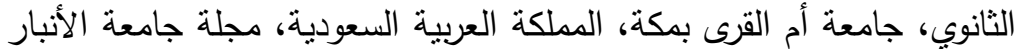

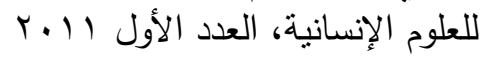

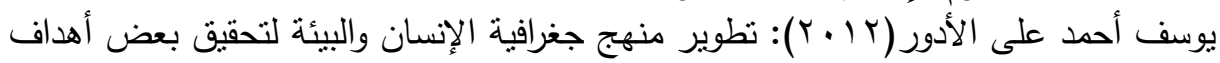

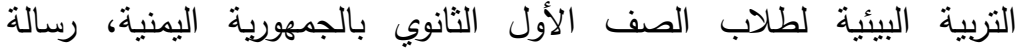

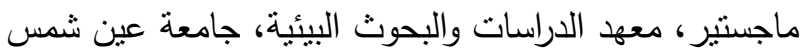

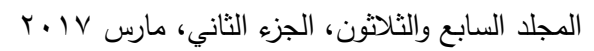


رشا الخيسي وآخرون

Fisman 'L.(2005):" The effects of local learning on Environmental awareness in children". Journal of Environmental Education,(3):39.

Holliday, William (2001) : Nodeling in Science . science Scope, V25, N2.

Holtzer Gisele. ،2004 : Du francais fonctionnel au francais sur objectif specifique ‘Le Francais Dans Le Monde ،Cle International . Paris

Prince ‘Heather,(1999):" Experiential Environmental Education for primary Aged Chieldren " Report's, htt.www.eric.ed.gov .

Smith, Julie M., etal "Using Technology and Inquiry to Improve Student Understanding of Watershed Concepts" Journal of Geography, v105, n6, pp249-258, 2006 http://www.eric.ed.gov/ 
مجلة العلوم البيئية

معهذ الدراسات والبحوث البيئية - جامعة عين شمس البئ

\title{
IMPROVING FRENCH LANGUAGE CURRICLUM USING MODELING AND SIMULATION STRATEGY TO DEVELOPING SKILLS ENVIRONMENTAL FOR THE FOURTH GRAND PRIMARY SCHOOL STUDENTS
}

El Khamasey, Rasha, M. ${ }^{(1)}$; Mohamed, Reham, R. ${ }^{(2)}$ and El Deeb, Amany, $M$.

1) Faculty of Alson, Ain Shams University 2) Institute of Environmental studies and Research, Ain Shams University

\begin{abstract}
This study drives at developing curriculum of French language for primary grade-four using strategy of modeling and simulation for developing skills environmental of those students. In order to achieve that purpose, a checklist of the most important topics and environmental problems has been designed, that should be included within the French curriculum. A content analysis is used in terms of topics of (air pollution - the black cloud - non-renewal resources depletion - oil depletion - water pollution - water scarcity). A scale of Skills environmental is designed and a conception of proposed two units in French is suggested, selecting unit four and six for application. These units are taught in (street - garden) containing some environmental issues and problems and using modeling and simulation strategy. The study uses the quasi-experimental method to try the two units, using as well the descriptive method to analyze the objectives and content of the curriculum of both units. Results indicate significant statistical differences exist between average scores of the experimental and the control group regarding the post-application of scale environmental skill, in favor of the experimental group. The study suggests applying 250

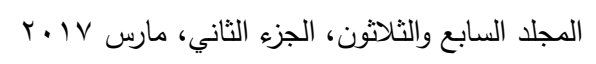


رشا الخميسي وآخرون

those proposed two units and the scale on other various educational stages since they have proved their efficacy.

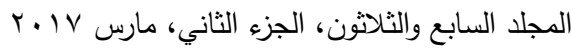

